\title{
Analysis of time-resolved wind-driven rain on an array of low-rise cubic buildings using large eddy simulation and an Eulerian multiphase model
}

\author{
A. Kubilay ${ }^{\mathrm{a}, \mathrm{b}, *}$, D. Derome ${ }^{\mathrm{b}}$, J. Carmeliet ${ }^{\mathrm{a}, \mathrm{b}}$ \\ ${ }^{a}$ Chair of Building Physics, Swiss Federal Institute of Technology ETHZ, Zurich, Switzerland \\ ${ }^{b}$ Laboratory for Multiscale Studies in Building Physics, Swiss Federal Laboratories for Materials Science and \\ Technology(Empa), Dübendorf, Switzerland \\ * Corresponding author: Aytaç Kubilay, Laboratory for Multiscale Studies in Building Physics, Swiss Federal Laboratories \\ for Materials Science and Technology (Empa), Überlandstrasse 129, CH-8600, Dübendorf, Switzerland. Tel.: +41 58765 \\ 4276; E-mail address: aytac.kubilay@empa.ch
}

\begin{abstract}
Time-resolved wind-driven rain (WDR)load is investigated on an array of low-rise cubic buildings using an Eulerian multiphase (EM) model together with large eddy simulation (LES). The influence of wind-flow unsteadiness on the unsteady behavior of raindrops and the WDR intensity is discussed in detail. The wind-flow field predicted with LES has been validated with wind-tunnel measurements. The mean WDR intensity values obtained using the EM model are found to be in agreement with in-situ WDR measurements. The time-resolved simulations show that the instantaneous specific catch ratio values of smaller droplets fluctuate a lot around their mean values due to higher influence of turbulence. Instantaneous specific catch ratios for the smallest raindrops are mainly dictated by local turbulent structures present in the shear layer or below the rooftop level. On the other hand, the motion of larger raindrops is mainly influenced by the larger-scale motions above the cubes. It is also shown that, running means of the specific catch ratio over a time window of 100-300 s of physical time stabilize to a constant value.
\end{abstract}

Keywords: Wind-driven rain, Raindrop behavior, Computational fluid dynamics (CFD), Eulerian multiphase model, Large eddy simulation (LES)

\section{Introduction}

Wind-driven rain (WDR) is the type of rain which has a horizontal velocity vector due to the effect of wind flow occurring at the same time. WDR is one of the most important moisture sources that influence the hygrothermal performance and the durability of building facadeswith potential negative effects. Rain can lead to film runoffon building facades, which may cause leakage, or be absorbed by the facade, which may transport moisture to internal layers of the facade causing moisture damage.Through such mechanisms, several undesired phenomena in buildings can occur, such as frost damage at exterior wall surfaces (Van Balen 1996; Franke et al. 1998), erosion of building materials (Tang et al. 2004; Erkal et al. 2012), moisture-induced salt migration (Charola and Lazzarini 1986; Franke et al. 1998), discoloration by efflorescence (Franke et al. 1998), surface soiling (Davidson et al. 2000; Etyemezian et al. 2000) and biological growth such as algae growth on the exterior (Barberousse et al. 2007)and mold growth onthe interior wall surfaces(Abuku et al. 2009b), etc. Accurate prediction of raindrop behavior in the air has the potential to improve the understanding of such phenomena.

(C) 2016. This manuscript version is made available under the Elsevier user license

http://www.elsevier.com/open-access/userlicense/1.0/ 
WDR intensity on a building is governed by a wide range of parameters, such as building geometry, environment topography, position on the building facade, wind speed, wind direction, rainfall intensity and raindrop-size distribution (Blocken and Carmeliet 2002).A typical time-averaged surface wetting pattern shows large gradients both vertically and horizontally on a single windward facadeof a simplified rectangular building (Blocken and Carmeliet 2006).In multibuilding environments, the wind-flow pattern around one building isfurther influenced by other buildings and becomes more complex. As a result, the presence of neighboring buildings influence the WDR exposure on each other (Blocken et al. 2009; Kubilay et al. 2014b, 2015b). In addition to the large-scale influences of building size and shape and of surrounding environment, small-scale facade details have a considerable impact on WDR intensity (Kubilay et al. 2016a).

The works of various researchers in the past have fundamentally contributed to a better understanding and modeling of WDR(Blocken 2014; Blocken and Carmeliet 2010). Computational fluid dynamics (CFD) simulations of WDR are either using a Lagrangian Particle Tracking (LPT) model where individual raindrops are tracked (Choi 1993; Hangan 1999; Etyemezian et al. 2000; Blocken and Carmeliet 2002; van Mook 2002; Tang and Davidson 2004; Blocken and Carmeliet 2006, 2007; Abuku et al. 2009a; Briggen et al. 2009; van Hooff et al. 2011; Foroushani et al. 2014) or an Eulerian multiphase (EM) model where the rain is regarded a continuum (Huang and Li 2010; Kubilay et al. 2013, 2014b, 2015a, 2015b, 2016a).A common aspect of the large number of studies based on both the LPT and EM modelsisthat the wind-flow field around buildings is calculated using Reynolds-averaged Navier-Stokes (RANS) models. RANS models have numerical deficiencies around the windward edges and in the wake of the buildings (Murakami 1990, 1993; Tominaga et al. 2008a; Tominaga et al. 2008b), such as the size of the wake and the location of reattachment.Large eddy simulation (LES) is expected to calculate the Reynolds stresses more accurately and, hence, expected to give a more accurate representation of separated flows. The more accurate flow estimation by LES in separation regions can also improve the accuracy of the WDR load on downstream buildings in multi-building configurations. Furthermore, distributions of WDR intensityobtained based on RANS models are usually steady-state values, which are extended into the time domain using the method proposedby Blocken and Carmeliet (2002).WDR calculations with LES have the potential to give more insight in the transient behavior of WDR.

The calculation of WDR intensity in LPT models is usually based on the steady-state streamtube approach. The streamtube approach calculates the WDR intensity based on the conservation of mass between the two ends of the streamtube, relying on the fact that the raindrop trajectories will not intersect each other in steady-state conditions. Therefore, this approach is not applicable when unsteady WDR analyses are performed. Chang and Wu (2003) performed a WDR study on different street canopies using LES with an LPT model, where they used time-averaged raindrop trajectories for their analyses.An unsteady WDR simulation with LES using an LPT model would require larger numbers of raindrop injections, increasing the computational cost significantly. In the present study, an EM model is used for WDR, where the continuity and momentum equations are solved for the rain phases which give the distribution of rain phase fraction and rain velocity in the computational domain. EM model provides a simpler integration of unsteady simulations of wind flow in WDR calculation in order to get instantaneous values for rain phase fraction and velocity. To the knowledge of authors, there is only one study so far which analyzes wind-driven rain using LES based on an EM model(Huang and Li 2012), which performs a validation study on a stand-alone low-rise building and compared WDR intensity estimated with RANS and LES on a stand-alone high-rise building.

The present studyanalyzesthe unsteady WDR exposure of a regular array of low-rise cubic buildings using LES calculations.The geometry is similar to the one that is used for field experiments of WDR (Kubilay et al. 2014a) and validation of the EM model based on steady RANS calculations (Kubilay et al. 2014b). Detailed investigation of the timeresolved wind-driven rain intensity is performed on two buildings of the array configuration. Furthermore, the response of instantaneous wind-driven rain on the local instantaneous wind-flow features is analyzed.In section 2,the governing 
equations of the multiphase model are presented. Section 3 presents the validation studies performed for the wind-flow field and the WDR. Section 4describes the building geometry,the computational domain and grid, the boundary conditions, the solution strategy and the solver settings. Section 5 presents the simulation results and the main findings of the study.

Finally, sections 6 and 7provide a discussion and conclusion, respectively.

\section{Numerical model for WDR simulation}

\subsection{Governing equations of wind}

In the present study, large eddy simulation(LES) is used for the incompressible wind-flow simulations, resolving the largescale motions while modeling the small-scale ones.In the present study, isothermal conditions are considered based on the assumption of cloudy conditions and presence of strong winds. The filtered continuity and momentum equations are as shown in Eqs. (1)and(2):

$$
\begin{aligned}
& \frac{\partial \overline{\overline{u_{i}}}}{\partial x_{i}}=0 \\
& \frac{\partial \overline{\overline{u_{i}}}}{\partial t}+\overline{\overline{u_{j}}} \frac{\partial \overline{\overline{u_{i}}}}{\partial x_{j}}+\frac{\partial \tau_{i j}}{\partial x_{j}}=-\frac{1}{\rho_{a}} \frac{\partial \overline{\bar{p}}}{\partial x_{i}}+v \frac{\partial^{2} \overline{\overline{u_{j}}}}{\partial x_{i} \partial x_{i}}
\end{aligned}
$$

where $u_{i}$ denotes the component of air velocity in the direction of the Cartesian coordinate $x_{i}(i=1,2,3), p$ the pressure, $\rho_{a}$ the density of air, $v$ the kinematic air viscosity and $\tau_{i j}$ the residual stress tensor.The double overbar denotes LES filtering. The residual stress tensor is modeled based on the Boussinesq approximation as follows:

$\tau_{i j}-\frac{2}{3} k_{r} \delta_{i j}=-2 v_{r} \overline{\overline{S_{i j}}}$

where $k_{r}$ the residual kinetic energy, $\delta_{\mathrm{ij}}$ the Kronecker delta, $v_{r}$ the residual viscosity and $S_{i j}$ the rate of strain tensor.In the present study, the residual viscosity, $v_{r}$, is calculated using the one-equation residual stress model by Yoshizawa (1985). Transport equation models perform better than zero-equation models such as the Smagorinsky model in cases with separating and reattaching flows and boundary layers. For this, an additional transport equation is solved as shown below:

$$
\frac{\partial k_{r}}{\partial t}+\overline{\overline{u_{j}}} \frac{\partial k_{r}}{\partial x_{i}}=\frac{\partial}{\partial x_{j}}\left(v_{r} \frac{\partial k_{r}}{\partial x_{j}}\right)-2 \tau_{i j} \overline{\overline{S_{i j}}}-\varepsilon
$$

where the terms on the right-hand side denote the residual turbulent transport, production and dissipation. Note that the residual stress term approaches zero in the limit of small grid spacing. As the contribution by the residual stress is smaller than the contribution by the resolved part, the modeling in LES leads to a smaller error potential, even in cases when the residual stress models are comparatively simpler than the eddy-viscosity models in RANS.The residual viscosity is calculated as follows:

$v_{r}=C_{k} k_{r}^{0.5} \Delta$ 
where, $C_{\mathrm{k}}$ is a model constant and $\Delta$ denotes the filter width.

\subsection{Governing equations of WDR}

Governing equations of WDR are solved together at each timestep with the governing equations of wind in order to estimate the unsteady WDR intensity on the buildings. Rain is considered to be composed of multiple phases, instead of a uniform phase, in addition to the air phase. Each class of raindrop size is treated as a different phase, as raindrops with similar size will interact with the wind-flow field in a similar way. For each separate rain phase defined in the Eulerian multiphase (EM) model, the following continuity and momentum equations are solved:

$$
\begin{aligned}
& \frac{\partial \alpha_{d}}{\partial t}+\frac{\partial \alpha_{d} \overline{\overline{u_{d, j}}}}{\partial x_{j}}=0 \\
& \frac{\partial \alpha_{d} \overline{\overline{u_{d, j}}}}{\partial t}+\frac{\partial \alpha_{d} \overline{\overline{u_{d, i} u_{d, j}}}}{\partial x_{j}}+\frac{\partial \alpha_{d} \tau_{d, i j}}{\partial x_{j}}=\alpha_{d} g_{i}+\alpha_{d} \frac{3 \mu_{a}}{\rho_{w} d^{2}} \frac{C_{d} \operatorname{Re}_{R}}{4}\left(\overline{\overline{u_{i}}}-\overline{\overline{u_{d, i}}}\right)
\end{aligned}
$$

where $d$ denotes the raindrop diameter, $\alpha_{d}$ the phase fraction of rain phase $d, u_{d, j}$ denotes the velocity component of rain phase $d, u_{i}$ the velocity component of wind in direction $i, \rho_{w}$ the density of water, $\mu_{a}$ is the dynamic viscosity of air, $g$ the gravitational acceleration, $C_{d}$ the drag coefficient. In Eq. (7), the terms on the left-hand side are the transient term and the filtered flux and the residual flux.The derivation of Eqs (6) and (7) are given in Kubilay (2014) and Kubilay et al. (2015a). The residualstress tensor for rain phased, $\tau_{\mathrm{d}, \mathrm{j} j}$, is modeled by defining a response coefficient, $C_{t}$, which relates it to the residual stress tensor for wind. Note that this approach is similar to the response coefficient method as introduced for RANS-based WDR models used in earlier studies (Kubilay et al. 2014b, 2015a, 2015b). However, the influence of the response coefficient method, and hence the residual stresses, is much smaller in LES simulation as a large part of the turbulence is actually resolved. Typically, the contribution of the residualstressesin LES is smaller than $20 \%$ of the overall turbulent energy (Pope 2000).The terms on the right-hand side in Eq. (7) represent the gravity and the drag forces. Drag coefficients are obtained based on the measurements of terminal velocities of water droplets by Gunn and Kinzer (1949). $\mathrm{Re}_{R}$ denotes the relative Reynolds number calculated using the relative velocity between the air and rain phases as follows:

$$
\operatorname{Re}_{R}=\frac{\rho_{a} d}{\mu_{a}}\left\|\mathbf{u}-\mathbf{u}_{d}\right\|
$$

where $\mathbf{u}$ denotes the air phase velocity vector and $\mathbf{u}_{\mathrm{d}}$ the rain phase velocity vector of rain phase $d$.

In the present study, raindrop diameters are assumed remain constant during their travel in the computational domain i.e. no evaporation, coalescence or breakup is considered. It is further assumed that the raindrops have a spherical shape. Rain phase calculations are one-way coupled with the air phase, with the effect of raindrops on the wind flow ignored. This is a valid assumption as the volumetric ratio of rain in air is below $1 \times 10^{-3}$ for rainfall intensities up to $20 \mathrm{~mm} / \mathrm{h}$ and below $1 \times 10^{-2}$ for even the most severe cases according to the study by de Wolf (2001). 


\subsection{WDR parameters}

The amount of rain reaching a surface and wetting it due to raindrops of specific size $d$ is commonly quantified by the specific catch ratio, $\eta_{d}(d)$, which is obtained by normalizing the WDR intensity, $R_{w d r}$, with the unobstructed horizontal rainfall intensity, $R_{h}$. The distribution of catch ratios on building surfaces is influenced by building geometry, environment topography, position on the building facade, wind speed, wind direction, rainfall intensity and raindrop-size distribution (Choi 1993, Blocken and Carmeliet 2002). The specific catch ratio for rain phase $d$ on the surfaces of the computational domain can be calculated using the following relation (Huang and Li 2010):

$\eta_{d}(d)=\frac{R_{w d r}(d)}{R_{h}}=\frac{\alpha_{d}\left|V_{n}(d)\right|}{R_{h} f_{h}\left(R_{h}, d\right)}$

where $f_{h}\left(R_{h}, d\right)$ denotes the raindrop-size distribution through the horizontal planeand $\left|V_{n}(d)\right|$ the velocity magnitude of the rain phase in the direction normal to the building surface.Rain phase volumetric fraction $\alpha_{d}$ and the normal velocity $\left|V_{n}(d)\right|$ are obtained by solving Eqs. (6) and (7). The probability of a raindrop size $f_{h}\left(R_{h}, d\right)$ is obtained based on the study of Best (1950).

\section{Validation of the numerical models}

The time-resolved WDR study presented in this paper is based on two separate validation studies for flow around a regular array of 9 cubes: flow measurements at wind-tunnel scale (cubes of $5 \mathrm{~cm}$ ) and measurements of WDR in field experiments (cubes of $2 \mathrm{~m}$ ). The measurement setups for both studies are shown in Fig. 1. The wind-tunnel measurements are performed with the stereoscopic particle image velocimetry (PIV) system in the ETHZ/Empa atmospheric boundary layer (ABL) wind tunnel in Dübendorf, Switzerland(Kubilay 2014; Kubilay et al. 2016b). Time-resolved and time-averagedflow

measurements are performedon two vertical planes parallel to the main flow direction: the vertical center plane and a plane between two rows of cubes.The measured flow parametersarecompared with the ones calculated using theone-equation residual stress model by Yoshizawa (1985).LES requires the specification of transient turbulent conditions at the inlet of the domain at all scales down to the spatial scale, i.e. the grid scaleand the temporal scale, i.e. the time step, of the simulation. In the present study, the method of random spots by Kornev and Hassel (2007) is used to synthesize the inflow turbulence. This method of random spots generates fluctuations with prescribed time-averaged wind-velocity profile, one-point cross correlations between fluctuating components of velocity and streamwise integral length scale. The generated profiles of time-averaged components of Reynolds stresses and velocity at the inlet are found to have a good match with the approachflow profiles obtained in the wind tunnel(Fig. 8.8 in Kubilay 2014).

Fig. 2 presents the comparison of mean streamwise velocity, turbulence kinetic energy and turbulence length scale along vertical lines 1-3 located in the two measurement planes(Kubilay 2014; Kubilay et al. 2016b). LES has in general a goodagreement with the measured values in terms of mean velocity and turbulence kinetic energy in both planes. In the vertical centerplane (Fig. 2a), LES overpredicts the turbulence kinetic energy along the large part of line 1.This may be related to the turbulence synthesizedat the inlet boundary changing by the time the flow reaches the positions of the cubes. When synthesizing the inflow turbulence, only a scalar integral length scale is prescribed at the inlet, which may not be capturing the temporal statistics at the inlet completely. Nevertheless, the turbulence length scales obtained by LES mostly agree with the measured values along the three lines in the vertical center plane. LES is able to predict the lower length scales below the rooftop level and the higher ones above the cubes as measured in the wind tunnel. This is an important observation since the present study focuses on the response of raindrops to the time-varying turbulent flow structures 
observed around buildings. On the other hand, turbulence length scales have larger discrepancy in the plane between the rows of cubes where the turbulence is not influenced directly by a geometrical obstacle. Overall, given that the timeresolved WDR study in the remainder of the paper is performed on a similar arrangement of cubes, we can assume a similar agreement could also be obtained at the scale of the field measurements.

The field measurements of WDR on the geometry composed of an array of low-rise cubic building models (Fig. 1(b)) have taken place between May - October, 2013 (Kubilay et al. 2014a) on the campus of Empa in Dübendorf, Switzerland. A total of 18 WDR gaugesare positioned on two cubes. The gauges are composed of collectors located outside and tipping bucket sensors located inside the cubes. The rain events recorded during this period are used to validate the EM model, which is used for the estimation of the WDR intensity on building facades (Kubilay et al. 2014b). During the validation study, 10min averaged wind speed and wind direction as well as 10-min summed horizontal rainfall amount and the WDR amount are used from the measured data.Fig. 3compares the measured and the numerical cumulative WDR amounts for the WDR gauges located on upstream and downstream cubesthroughout the rain event on September 16-19, 2013. The numerical estimations follow the experimental data very accurately except for a short duration at the end, with spikes of short rainspells, which causes larger discrepancy for some locations on the facade. The average discrepancy is found to be $6.5 \%$ for the upstream cube and $12.0 \%$ for the downstream cube.A further validation studyisalso performed on a geometry composed of two parallel wide building models (Kubilay et al. 2015b).The validation studies show that the EM model cansuccessfully predictthe response of different-size raindrops to the wind-flow field, considering the fact that the parameters such as wind direction, wind speed and rainfall intensity change considerably during a rain event.

\section{Simulation settings and parameters}

\subsection{Computational domain and grid}

The computational domain for the time-resolved WDR simulation is composed of a regular array of 9 identical low-rise cubic building models as shown inFig. 4.The geometry is identical to the one used for field experiments of WDR byKubilay et al. (2014a). The cubic building models have dimensions $\mathrm{H} \times \mathrm{H} \times \mathrm{H}=2 \times 2 \times 2 \mathrm{~m}^{3}$ and they are spaced $\mathrm{H}=2 \mathrm{~m}$ apart from each other.The cubesare located $5 \mathrm{H}$ away from the inlet and side boundaries, and $10 \mathrm{H}$ away from the outlet boundary.The size of the computational domain is sufficiently large to contain the largest turbulence length scale (20 m).

As the LES filter size is related to the grid-cell size, i.e. implicit filtering, the choice of size of the grid cells isimportant. If the grid cells are too coarse, turbulent motions will not be sufficiently resolved. On the other hand, if the grid cells are too fine, the simulation will be computationally too expensive. Furthermore, the errors due to numerical discretization or toresidual stress modeling cannot be easily distinguished (Celik et al. 2005; Freitag and Klein 2006; Gousseau et al. 2013). In the present paper, the computational grid is chosen following a grid-sensitivity analysis and consists of 5022002 cells.Only cubic grid cells are used throughout the computational domain so that the LES filter size is the same in all directions. The cross section of the computational grid is shown in Fig. 5 . The first cell height on the ground is $0.008 \mathrm{H}$ and on the cube surface is $0.007 \mathrm{H}$. The average $y^{+}$is 25 on the ground surface and 23 on the cube surfaces.These values are slightly larger than the requirements to resolve the viscous sublayer on the wall boundaries. However, this is acceptable in the present study as the turbulence is mainly generated due to the detachment at sharp edges and not due to wall shear and given that the main objective is to analyze the behavior raindrops. The resolved turbulence kinetic energy is over $80 \%$ of the total turbulence kinetic energy except for very small partsofseparation regions. Furthermore, the grid cells are smaller than $1 / 4^{\text {th }}$ of the integral length scale, following the guideline by Davidson (2009). 


\subsection{Boundary conditions}

\subsubsection{Boundary conditions for wind phase}

The time-averaged wind-velocity is assumed to have a neutrally stratified atmospheric boundary layer log-law profile:

$U(y)=\frac{u_{A B L}^{*}}{\kappa} \ln \left(\frac{y+y_{0}}{y_{0}}\right)$

where $U(y)$ denotes the wind speed at a height $y$ above the ground plane, $u^{*}{ }_{A B L}$ the atmospheric boundary layer (ABL) friction velocity, $\kappa$ the von Karman constant ( 0.42 in the present study) and $y_{0}$ the aerodynamic roughness length. In this study, $u^{*}{ }_{A B L} / U$ is taken 0.24 and $y_{0}$ is taken $0.49 \mathrm{~m}$.Inflow turbulence is generated using the method of random spots (Kornev and Hassel 2007). The Reynolds stresses at the inlet are obtained from the earlier validation study using RANS modeling (Kubilay et al. 2014b)by assuming isotropic turbulence at the inletand the integral length scale at the inlet is obtained with:

$l=C_{\mu}^{3 / 4} \frac{k^{3 / 2}}{\varepsilon}$

as defined in RANS $k-\varepsilon$ model.

A constant static gauge pressure of $0 \mathrm{~Pa}$ is used at the outlet boundary. Limiters are imposed at the outlet to prevent inflow induced by energetic exiting vortices. The side boundaries in the spanwise directions are periodic for all transported quantities. The top boundary is a symmetry plane. For the ground boundary, Van Driest damping is used. Note that the use of smooth wall functions, as well as the wall functions with roughness modifications, in LES, are questionable as the wall functions are mainly developed for the mean flow field, where the logarithmic law of the wall is applicable. However, the instantaneous wall-shear stress can be different from the values indicated by the law of the wall (Wang and Moin 2000). Nevertheless, there is research on-going on the development of wall functions for LES calculations (Piomelli et al. 1989; Werner and Wengle 1991). In the present study, no wall functions are used for the ground surface, as well as for the building surfaces.The inlet boundary condition for the residual kinetic energy $k_{\mathrm{r}}$ is set to a uniform value, much smaller than the total turbulence kinetic energy.

\subsubsection{Boundary conditions for rain phases}

The values of rain-phase fraction, $\alpha_{d}$, and the rain-phase velocity, $u_{d, j}$, are defined at the inlet and top boundaries for each rain phase $d$.The phase fraction for rain phase $d$ can be calculated as in Eq. (12), where $V_{t}(d)$ represents the terminal velocity of a raindrop with diameter $d$ :

$\alpha_{d}=\frac{R_{h} f_{h}\left(R_{h}, d\right)}{V_{t}(d)}$

The vertical inlet rain phase velocity component is set equal to the terminal velocity for that phase. The horizontal component ofrain-phase velocity is set such that there is a local force equilibrium between the rain and wind phases so that the droplets neither accelerate nor decelerate in an unobstructed computational domain. 
The boundary conditions for the rain-phase fraction and the rain-phase velocity at the building walls, on the ground and at the outlet are set in such way that the normal gradient of the phase fraction, $\partial \alpha_{d} / \partial n$, equals zero when the normal wind velocity vector is pointing out of the calculation domain, and the values of the phase fraction, $\alpha_{d}$, are equal to zero when the normal wind velocity vector is pointing into the domain. With these boundary conditions, the interaction between the raindrops and the walls are not modeled and the raindrops leave the domain as soon as they hit a wall boundary, avoiding any inflow of rain phase into the domain due to possible recirculation regions.

The inlet boundary conditions for the velocities and volume fractions of the rain phases are mean values, i.e. the inflowturbulence generator is not used for the rain phases, because the length scales and Reynolds stresses are unknown for the rain phases. It is assumed that at a distance sufficiently away from the buildings, the rain phases are uniform and continuous and, hence, the phase fraction of rain phases, $\alpha_{d}$, is uniform. It is also assumed that $\alpha_{d}$ values adapt to the unsteady windflow field within the computational domain before they reach the buildings.

\subsection{Solution strategy}

The unsteady wind-flow field around the building is solved for a mean wind-speed of $U=1 \mathrm{~m} / \mathrm{s}$ at the cube topheight. The choice of wind speed is mainly based on computation time, as higher wind speeds would require shorter timesteps. The chosen value is also representative as the wind speed is lower than that $32 \%$ of the time during rain in the city of Zurich for a typical meteorological year (Remund et al. 2014). The governing equations of rain phases for raindrop diameter values of $0.3 \mathrm{~mm}, 1.0 \mathrm{~mm}$ and $2.0 \mathrm{~mm}$ are solved simultaneously with the wind-flow at each time step. Instantaneous specific catch ratio valueson the cubes are calculated using the instantaneous rain phase velocities and phase fractions as defined in Eq. 9.

The calculations are performed initially for 3600 s of physical time, which corresponds to 90 times the mean flow residence time in the computational domain. Further calculations do not lead to significant changes in flow parameters such as statistically steady-state velocity and Reynolds stress components. Afterwards, the calculations are performed furtherfor $300 \mathrm{~s}$ of physical time, from which the results in section 5 are obtained and analyzed.

\subsection{Solver settings}

OpenFOAM ${ }^{\circledR} 2.2$ is used as the CFD code.The pressure-velocity coupling for the wind-flow solution is taken care of with the Pressure Implicit with Splitting of Operators (PISO) algorithm. Second-order discretization schemes are used for both the convection terms and the viscous terms of the governing equations. Time step is set to $2 \mathrm{~ms}$ so that the maximum Courant number, $C$, is less than 0.3 for wind, less than 0.4 for 0.3 -mm droplets, less than 0.8 for 1.0 -mm droplets and less than 1.0 for 2.0-mm droplets:

$$
C=\frac{u \Delta t}{\Delta x}
$$

where $u$ denotes the magnitude of the velocity, $\Delta t$ the time step and $\Delta x$ the cell size.

\section{Results}

\subsection{Time-averaged flow fields of wind and rain}


Fig. 6presents the time-averaged contours of magnitude of wind speed as well as the streamwise wind velocity profiles in the centerplane. The separation region above the rooftop of cube 2 is clearly visible. Separation regions above cubes 5 and 8 are much smaller in comparison. The wind-flow field in the region between cubes 2 and 5 is very similar to the one between cubes 5 and 8. The wind-flow field presented in Fig. 6 can be divided in two general regions: 1) the flow above the roof height with high velocity and 2) the flow below the roof height with recirculation regions and low velocity in between the cubes. The shear layer above the rooftop level extends to about $\mathrm{y}=1.2 \mathrm{H}$.

Fig. 7 compares the time-averaged streamlines of raindrops impinging on cube 2 with the ones impinging on cube 8occurring in a wind-flow field with a reference wind speed of $1 \mathrm{~m} / \mathrm{s}$. The positions indicated as A, B and C represent the WDR gauges in the field measurements (Kubilay et al. 2014a) on the windward facades of cube 2 and 8 . The difference in approach windflow for the two cubes leads to a difference between the time-averaged trajectories of raindrops. The streamlines of $0.3 \mathrm{~mm}$ droplets differ clearly both above and below the rooftop level. Above the rooftop, the raindrops are clearly influenced by the larger separation region on the rooftop of cube 2, where they experience an upward acceleration, followed by a decrease in streamwise velocity due to the larger separation region on the rooftop of cube 2 . The $0.3 \mathrm{~mm}$ droplets also show a different behavior below the rooftop $(y=\mathrm{H})$, where the droplets move further away from the facade of cube 8 due to the recirculation region between cubes 5 and 8 . As the raindrop size increases, the droplets impact the facade with larger angles with respect to the facade normal. Also with increasing raindrop size, the wind-flow field below the roof level has a smaller influence on the raindrop streamlines. In the case of $2.0 \mathrm{~mm}$ raindrops, there is almost no influence of the different wind-flow fields below the roof level, for their trajectories upstream of cubes 2 and 8.

Table 1and Table 2present the time-averaged specific catch ratio values for $d=0.3,1.0$ and $2.0 \mathrm{~mm}$ at different parts of the facade of cubes 2 and 8, respectively, as illustrated in Fig. 7. The values within the brackets indicate the standard deviation of the specific catch ratio. Similar values of specific catch ratio are observed for both cubes. The largest difference between the cubes is observed for the $0.3 \mathrm{~mm}$ raindrops at the upper part of the facade, which has larger mean and standard deviation values on cube 8 compared to cube 2.The larger values on cube 8 could be due to the turbulence in the shear layer between cubes 5 and 8 . Table 1 and Table 2 also show that the spatial distribution of specific catch ratio becomes more homogeneous over the facades as the raindrop size increases. Similarly, the standard deviations tend to decrease as the raindrop size increases.

\subsection{Time-resolved flow fields of wind and rain}

Fig. 8shows the contours of magnitude of instantaneous wind speed in the centerplane at time instants $t=100-180 \mathrm{~s}$ with 10 -second increments. There are large-scale motions above the roof level, where the instantaneous wind speeds can get larger than $2.0 \mathrm{~m} / \mathrm{s}$ just above the roof level of the cubes. On the other hand, the small-scale motions are visible in regions between the cubes, where the wind speed is much lower.

Fig. 9 shows streamlines of raindrop size of $0.3 \mathrm{~mm}$ at different time instants. The equidistant starting locations of the streamlines are at the inlet and top boundaries of the computational domain in the centerplane and away from the influence of buildings. The time-averaged streamlines are presented in Fig. 9(a) as reference. The raindrops of diameter of $0.3 \mathrm{~mm}$ are

influenced heavily by the local flow field. The instantaneous streamlines can deviate strongly from the mean both above the roof level, where the length scales are larger, and below the roof level, where the length scales are smaller as shown in Fig. 9(b-d). Besides, the influence of local structures on the wind-flow fields is clear as in Fig. 9(b), where a sweeping-like behavior is observed between the two downstream cubes. 
Fig. 10shows streamlines of raindrop size of $1.0 \mathrm{~mm}$ at different time instants. The time-averaged streamlines are presented in Fig. 10(a) as reference. The instantaneous streamlines for the raindrop size of $1.0 \mathrm{~mm}$ are more straight and parallel to each other compared to the ones for $0.3 \mathrm{~mm}$ droplets. In general, the instantaneous streamlines do not show significant differences compared with the time-averaged streamlines shown in Fig. 10(a), especially below the roof level. The deviations from the time-averaged streamlines are mostly due to the presence of larger turbulent scales above the roof level.

\subsection{Analysis of instantaneous specific catch ratio}

Fig. 11shows the instantaneous specific catch ratio values as well as the running means over time from the start $(t=0)$ for the 3 raindrop sizes, surface-averaged over the square-shaped areas A, B and C,representing WDR gauges (Kubilay et al. 2014a). The fluctuations in instantaneous specific catch ratio are significantly larger for the $0.3 \mathrm{~mm}$ droplets at position A, as also shown by the standard deviations in Table 1. The fluctuations in specific catch ratio decrease as the raindrop size increases. This is due to the fact that smaller raindrops are influenced more by the fluctuations in the wind-flow field than larger raindrops are. Fig. 12shows instantaneous specific catch ratio values, as well as the running means, surface-averaged over areas A, B and C on the windward facade of cube 8.Overall, similar conclusions can be obtained in terms of the instantaneous specific catch ratio values as for cube 2. The biggest difference is for the specific catch ratio of $0.3 \mathrm{~mm}$ droplets, showing more fluctuations around the mean value with a standard deviation that is larger than the one on cube 2 .

Both Fig. 11 and Fig. 12 show that, for all raindrop sizes and facade positions, the running mean of specific catch ratios are relatively stable after the initial 100-300 s.If one is only interested in the time-averaged values (as mostly done in previous WDR studies), the commonly-used 10-min averaging of meteorological data is valid. The only exception may be rain events where the meteorological conditions such as wind direction and wind speed change a lot during these time intervals. In those cases, the meteorological conditions may change so fast that the actual catch ratio may be above or below the mean value,increasing the discrepancy between the numerical and experimental WDR intensities.

Furthermore, both in Fig. 11 and Fig. 12, the high and low spikes in the instantaneous catch ratio values tend to take place at similar times, and this becomes more apparent for large droplet sizes. This can be investigated in detail by following the specific catch ratio on cube 8 between time instants 220-235 s as well as the corresponding instantaneous wind-flow fields as shown inFig. 13.Fig. 13(a) shows the specific catch ratio for the three raindrop sizes for the upper position A on cube 8, whereasFig. 13(b) shows the corresponding vector fields in the vertical centerplane between time instants 226-231 s. Color scale in Fig. 13(b) indicates the magnitude of wind speed.For all raindrop sizes, there is an overall increase of the specific catch ratio as a high-velocity large-scale structure is observed to move towards cube 8 at about $y=2-3 \mathrm{H}$ height. The amount of the increase in specific catch ratio is smaller for larger raindrops during the time interval 220-235 s. Also, especially for the $0.3 \mathrm{~mm}$ raindrops, the increase is clearly interrupted by several local minima. At $\mathrm{t}=226 \mathrm{~s}$ and $227 \mathrm{~s}$, the local wind-velocity vectors are pointing towards the upper part of the windward facade of cube 8 with a relatively large velocity. This correlates with the steep increase in specific catch ratios for the smaller raindrops of $0.3 \mathrm{~mm}$ and $1.0 \mathrm{~mm}$ between $\mathrm{t}=225-227 \mathrm{~s}$. On the other hand, no significant difference is observed for $2.0 \mathrm{~mm}$ raindrops during the same time interval. Between $\mathrm{t}=228-230 \mathrm{~s}$, wind velocity is lower near the upper part of cube 8, during which the specific catch ratio decreases for $0.3 \mathrm{~mm}$ raindrops. On the other hand, an increase is observed for larger raindrops of 1.0 and $2.0 \mathrm{~mm}$ at $\mathrm{t}=230 \mathrm{~s}$. This increase becomes more evident after $\mathrm{t}=230 \mathrm{~s}$, when the large-scale motion at $\mathrm{y}=2-3 \mathrm{H}$ heightreaches cube 8.

These results show that the larger raindrops are not influenced much by the small-scale turbulent structures near the cubic buildings. The specific catch ratios for larger raindrops are mainly dictated by the mean wind-flow (as shown in Fig. 7) as 
well as the large-scale turbulent motions far above the cubes. On the contrary, the specific catch ratio for the smallest raindrops are mainly dictated by local turbulent structures in the shear layer or below the rooftop level. This can be further confirmed by comparing correlation coefficient $R$ for specific catch ratio over time:

$R\left(d_{i}, d_{j}\right)=\frac{C\left(d_{i}, d_{j}\right)}{\sqrt{C\left(d_{i}, d_{i}\right) C\left(d_{j}, d_{j}\right)}}$

where $C\left(d_{i}, d_{j}\right)$ denotes the covariance of specific catch ratio at a certain facade position, i.e. $\mathrm{A}, \mathrm{B}$ or $\mathrm{C}$, between two different raindrop sizes $d_{i}$ and $d_{j}$. A higher correlation coefficient means a higher similarity between two signals over time. Fig. 14 shows the correlation coefficientsbetween specific catch ratios of different raindrop sizeson cube 8 . The largest correlation coefficient is between the two larger raindrop sizes, with a value around 0.9 for all three positions on the windward facade.The correlation coefficients decrease as the difference in raindrop size increases and as smaller raindrops are involved. Furthermore, correlation coefficients are generally lower at lower positions on the facade. This is due to the fact that, for the lower positions, the raindrops have more time to adapt to the small-scale motions in region between the cubes. These results show that turbulence effects for a certain raindrop size need to be taken into account if they are influenced by the local small-scale turbulent fluctuations near the facade. For raindrops smaller than $1.0 \mathrm{~mm}$, turbulence influences the raindrop motion, whereas no significant influence is observed for $2.0 \mathrm{~mm}$ raindrops, at least for low-rise buildings.

\section{Discussion}

The present study is limited in terms of the number of rain phases as well as the number of wind directions in order to decrease the computational cost. The time required for the solution of the WDR model with LES is much longer than it is with RANS. The calculation of the $300 \mathrm{~s}$ of physical time in the present study took about 82 hours on a parallel run with 80 processors, excluding the time required for the calculation of the initial wind-flow field. As a comparison, the complete analysis of the RANS-based WDR study in Kubilay et al. (2014b) on the same geometry took about 108 hours on 16 processors, including 3 wind directions, 5 wind speeds and 17 raindrop sizes. On the other hand, LES calculation has the advantage of providing the standard deviation as well as the maximum and minimum values of specific catch ratio values on the facade, which can be useful. Furthermore, LES allows avoiding the well-known discrepancies of RANS $k-\varepsilon$ models, e.g. overestimation of turbulence kinetic energy values estimated at the edges of a bluff-body (Murakami 1990, 1993; Tominaga et al. 2008a; Tominaga et al. 2008b).

Note that the instantaneous streamlines of rain phases in the present study are different than the actual trajectories of raindrops. It is only for a time-averaged flow field that streamlines coincide with the trajectories. Instantaneous streamlines of the rain phases are lines that are tangent to the instantaneous velocity vector field of rain phases. Hence, a real raindrop at a start point of a streamline will follow a different trajectory as it falls because the wind-flow field will change in the meantime. Therefore, the instantaneous streamlines presented in Fig. 9 and Fig. 10give information on the behavior of droplets at a certain position, rather than the trajectory of a single droplet injected at the boundaries of the domain. Nevertheless, the shapes of the streamlines can give information on the flow fields of rain phases of different raindrops sizes and on how much the droplets are influenced by the instantaneous wind-flow field.

In the present study, the ground surface is taken as a smooth surface. Such an assumption may lead to an artificial acceleration of the approach wind flow. The use of wall functions with LES, with and without surface roughness modifications, is still on-going research. Therefore, in this study, we did not use wall functions in LES calculations. 
However, considering the relatively short upstream length of the computational domain (50 m), surface roughness would have only a limited influence on wind-driven rain intensity.

\section{Conclusion}

Unsteady WDR intensity on a regular array of low-rise cubic buildings is investigated using LES and validated models. The wind-flow field obtained with LES is validated by comparing with time-resolved and time-averaged wind-tunnel measurements. The EM model for WDR simulations has been validated using data from in-situ WDR measurements. Later, detailed investigation of the time-resolved WDR intensity is performed on two buildings within the array. LES is particularly interesting as it allows for the analysis of the unsteady behavior of raindrops. The main findings of the study can be summarized as follows:

- Specific catch ratio for the smallest raindrops are mainly dictated by local turbulent structures in the shear layer or below the rooftop level. On the other hand, the larger raindrops are not much influenced by these small-scale structures and their specific catch ratios are mainly dictated by the large-scale motions above the cubes. This is confirmed, first, visually by streamlines of droplets of different sizes and, second, numerically by the variation of instantaneous specific catch ratio and the correlation coefficient of specific catch ratio at different positions on the facade.

- Instantaneous specific catch ratio values of smaller droplets fluctuate significantly around the mean value, especially for smaller raindrops. LES study canalso provide the variation of the droplet impact speed and impact angle over time, in addition to WDR intensity.

- In WDR studies with steady RANS simulations, the WDR intensities are commonly calculated based on the assumption of 10-min time-averaged experimental timesteps. It is found that, after about 100-300 s, the mean specific catch ratio values stabilize around a constant value. This confirms that the assumption of steady-state 10-min experimental time steps is valid as long as the wind-flow conditions do not change abruptly during that time range of 100-300 s.

\section{Acknowledgments}

The research was supported through the Swiss National Science Foundation (SNF) - Project no. 135510. 


\section{References}

Abuku, M., Blocken, B., Nore, K., Thue, J.V., Carmeliet, J., and Roels, S. 2009a. On the validity of numerical wind-driven rain simulation on a rectangular low-rise building under various oblique winds. Build Environ 44 (3):621-632.

Abuku, M., Janssen, H., and Roels, S. 2009b. Impact of wind-driven rain on historic brick wall buildings in a moderately cold and humid climate: Numerical analyses of mould growth risk, indoor climate and energy consumption. Energ Buildings 41 (1):101-110.

Barberousse, H., Ruot, B., Yéprémian, C., and Boulon, G. 2007. An assessment of façade coatings against colonisation by aerial algae and cyanobacteria. Build. Environ. 42 (7):2555-2561.

Best, A.C. 1950. The size distribution of raindrops. Q J Roy Meteor Soc 76 (327):16-36.

Blocken, B. 2014. 50 years of Computational Wind Engineering: Past, present and future. J Wind Eng Ind Aerod 129:69-102.

Blocken, B., and Carmeliet, J. 2002. Spatial and temporal distribution of driving rain on a low-rise building. Wind Struct 5 (5):441-462.

Blocken, B., and Carmeliet, J. 2006. The influence of the wind-blocking effect by a building on its wind-driven rain exposure. $J$ Wind Eng Ind Aerod 94 (2):101-127.

Blocken, B., and Carmeliet, J. 2007. Validation of CFD simulations of'wind-driven rain on a low-rise building facade. Build Environ 42 (7):2530-2548.

Blocken, B., and Carmeliet, J. 2010. Overview of three state-of-the-art wind-driven rain assessment models and comparison based on model theory. Build Environ 45 (3):691-703.

Blocken, B., Dezso, G., van Beeck, J., and Carmeliet, J. 2009. The mutual influence of two buildings on their wind-driven rain exposure and comments on the obstruction factor. $J$ Wind Eng Ind Aerod 97 (5-6):180-196.

Briggen, P.M., Blocken, B., and Schellen, H.L. 2009. Wind-driven rain on the facade of a monumental tower: numerical simulation, fullscale validation and sensitivity analysis. Build Environ 44 (8):1675-1690.

Celik, I.B., Cehreli, Z.N., and Yavuz, I. 2005. Index of Resolution Quality for Large Eddy Simulations. Journal of Fluids Engineering 127 (5):949-958.

Chang, T.-J., and Wu, Y.-T. 2003. Wind driven rain distributions around street canopies. Journal of the American Water Resources Association 39 (3):545-562.Charola, A.E., and Lazzarini, L. 1986. Deterioration of brick masonry caused by acid rain. ACS Symp. Series 318:250-258.

Choi, E.C.C. 1993. Simulation of wind-driven-rain around a building. J Wind Eng Ind Aerod 46-47:721-729.

Davidson, C.I., Tang, W., Finger, S., Etyemezian, V., Striegel, M., and Sherwood, S.I. 2000. Soiling patterns on a tall limestone building: changes over 60 years. Environ Sci Technol 34 (4):560-565.

Davidson, L. 2009. Large eddy simulations: how to evaluate resolution. Int. J. Heat and Fluid Flow 30 (5):1016-1025.

de Wolf, D.A. 2001. On the Laws-Parsons distribution of raindrop sizes. Radio Sci 36 (4):639-642.

Erkal, A., D'Ayala, D., and Sequeira, L. 2012. Assessment of wind-driven rain impact, related surface erosion and surface strength reduction of historic building materials. Build Environ 57:336-348.

Etyemezian, V., Davidson, C.I., Zufall, M., Dai, W., Finger, S., and Striegel, M. 2000. Impingement of rain drops on a tall building. Atmos Environ 34:2399-2412.

Foroushani, M.S.S., Ge, H., and Naylor, D. 2014. Effects of roof overhangs on wind-driven rain wetting of a low-rise cubic building: A numerical study.J Wind Eng Ind Aerod 125 (0):38-51.

Franke, L., Schumann, I., van Hees, R., van der Klugt, L., Naldini, S., Binda, L., Baronio, G., van Balen, K., and Mateus, J. 1998. Damage atlas: classification and analyses of damage patterns found in brick masonry. European Commision Research report No 8, vol. 2, Fraunhofer IRB Verlag.

Freitag, M., and Klein, M. 2006. An improved method to assess the quality of large eddy simulations in the context of implicit filtering. Journal of Turbulence 7:N40.

Gousseau, P., Blocken, B., and van Heijst, G.J.F. 2013. Quality assessment of Large-Eddy Simulation of wind flow around a high-rise building: Validation and solution verification. Computers \& Fluids 79 (0):120-133.

Gunn, R., and Kinzer, G.D. 1949. The terminal velocity of fall for water droplets in stagnant air. J Meteorol 6 (4):243-248.

Hangan, H. 1999. Wind-driven rain studies. A C-FD-E approach. J Wind Eng Ind Aerod 81:323-331.

Huang, S., and Li, Q. 2012. Large eddy simulation of wind-driven rain on tall building facades. Journal of Structural Engineering 138 (8):967-983.

Huang, S.H., and Li, Q.S. 2010. Numerical simulations of wind-driven rain on building envelopes based on Eulerian multiphase model. $J$ Wind Eng Ind Aerod 98 (12):843-857.

Kornev, N., and Hassel, E. 2007. Method of random spots for generation of synthetic inhomogeneous turbulent fields with prescribed autocorrelation functions. Commun. Numer. Meth. Engng. 23:35-43.

Kubilay, A. 2014. Numerical simulations and field experiments of wetting of building facades due to wind-driven rain in urban areas. Ph.D. thesis, ETH Zurich, Switzerland.

Kubilay, A., Carmeliet, J., and Derome, D. 2016a. Computational fluid dynamics simulations of wind-driven rain on a mid-rise residential building with various types of facade details. Journal of Building Performance Simulation:1-19.

Kubilay, A., Derome, D., Blocken, B., and Carmeliet, J. 2013. CFD simulation and validation of wind-driven rain on a building facade with an Eulerian multiphase model. Build Environ 61:69-81.

Kubilay, A., Derome, D., Blocken, B., and Carmeliet, J. 2014a. High-resolution field measurements of wind-driven rain on an array of low-rise cubic buildings. Build Environ 78:1-13.

Kubilay, A., Derome, D., Blocken, B., and Carmeliet, J. 2014b. Numerical simulations of wind-driven rain on an array of low-rise cubic buildings and validation by field measurements. Build Environ 81 (0):283-295. 
Kubilay, A., Derome, D., Blocken, B., and Carmeliet, J. 2015a. Numerical modeling of turbulent dispersion for wind-driven rain on building facades. Environ Fluid Mech 15 (1):109-133.

Kubilay, A., Derome, D., Blocken, B., and Carmeliet, J. 2015b. Wind-driven rain on two parallel wide buildings: field measurements and CFD simulations. $J$ Wind Eng Ind Aerod 146:11-28.

Kubilay, A., Paterna, E., Derome, D., Blocken, B., and Carmeliet, J. 2016b. Flow around an array of cubes in a turbulent boundary layer: wind-tunnel measurements using stereoscopic PIV and numerical simulations. Submitted for publication.

Launder, B.E., and Spalding, D.B. 1974. The numerical computation of turbulent flows. Comput. Methods Appl. Mech. Eng. 3:269-289.

Murakami, S. 1990. Computational wind engineering. J Wind Eng Ind Aerod 36 (1-3):517-538.

Murakami, S. 1993. Comparison of various turbulence models applied to a bluff-body. J Wind Eng Ind Aerod 46-7:21-36.

Piomelli, U., Ferziger, J., Moin, P., and Kim, J. 1989. New approximate boundary conditions for large eddy simulations of wall-bounded flows. Phys. Fluids 1:1061-1068.

Pope, S.B. 2000. Turbulent flows: Cambridge University Press, UK.

Remund, J., Müller, S., Kunz, S., Huguenin-Landl, B., Studer, C., and Schilter, C. 2014. Handbook of METEONORM Version 7.0.

Tang, W., and Davidson, C.I. 2004. Erosion of limestone building surfaces caused by wind-driven rain: 2. numerical modeling. Atmos Environ 38 (33):5601-5609.

Tang, W., Davidson, C.I., Finger, S., and Vance, K. 2004. Erosion of limestone building surfaces caused by wind-driven rain: 1 . Field measurements. Atmos Environ 38 (33):5589-5599.

Tominaga, Y., Mochida, A., Murakami, S., and Sawaki, S. 2008a. Comparison of various revised k- $\varepsilon$ models and LES applied to flow around a high-rise building model with 1:1:2 shape placed within the surface boundary layer. J Wind Eng Ind Aerod 96 (4):389411.

Tominaga, Y., Mochida, A., Yoshie, R., Kataoka, H., Nozu, T., Yoshikawa, M., and Shirasawa, T. 2008b. AIJ guidelines for practical applications of CFD to pedestrian wind environment around buildings. J Wind Eng Ind Aerod 96 (10-11):1749-1761.

Van Balen, K. 1996. Expert system for evaluation of deterioration of ancient brick masonry structures. Sci Total Environ 189:247-254.

van Hooff, T., Blocken, B., and van Harten, M. 2011. 3D CFD simulations of wind flow and wind-driven rain shelter in sports stadia: Influence of stadium geometry. Build Environ 46 (1):22-37.

van Mook, F.J.R. 2002. Driving rain on building envelopes. In.: Ph.D. thesis, Eindhoven University of Technology, Eindhoven, The Netherlands.

Wang, M., and Moin, P. 2000. Dynamic wall modeling for LES of complex turbulent flows. Phys. Fluids 14:2043-2051.

Werner, H., and Wengle, H. 1991. Large eddy simulation of turbulent flow over and around a cube in a plane channel. Paper presented at the Proc. Eighth Symp. Turb. Shear Flows.

Yoshizawa, A. 1985. A statistically-derived subgrid-scale kinetic energy model for the large-eddy simulation of turbulent flows. Journal of the Physical Society of Japan 54 (8):2834-2839. 


\section{Figures}

a)

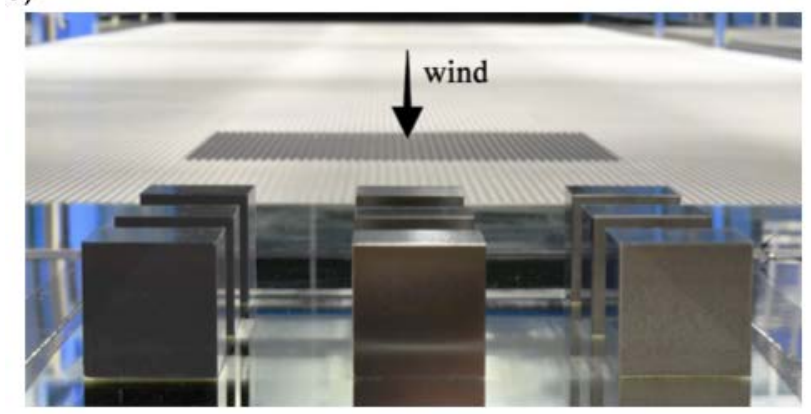

b)

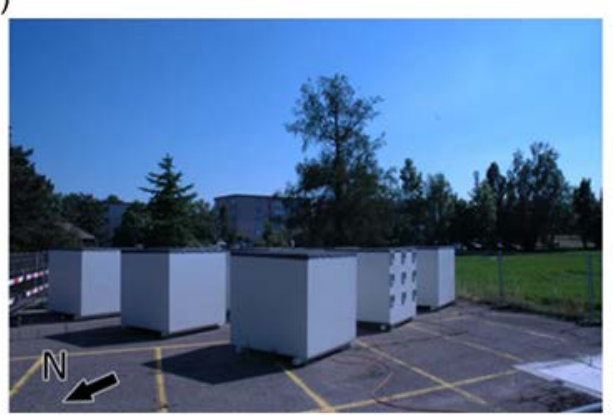

Fig. 1. The configurations of the regular arrays of equidistantly-placed cubes for a) wind-tunnel measurements of flow field (Kubilay 2014)and b) field measurements of wind-driven rain(Kubilay et al. 2014a). 

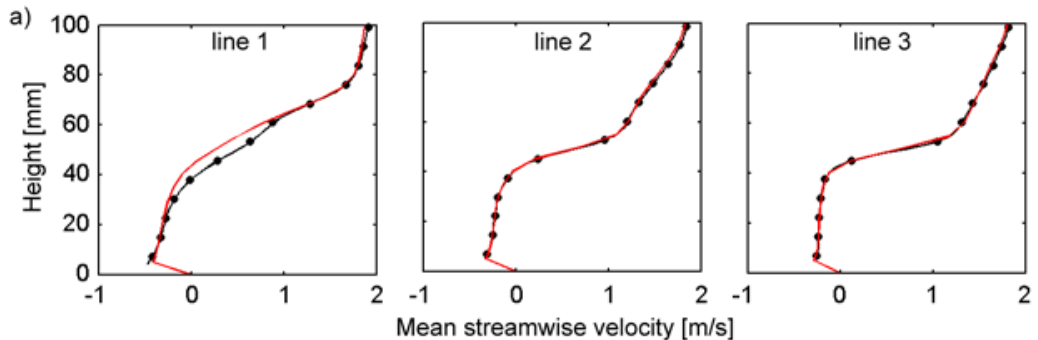

Top view
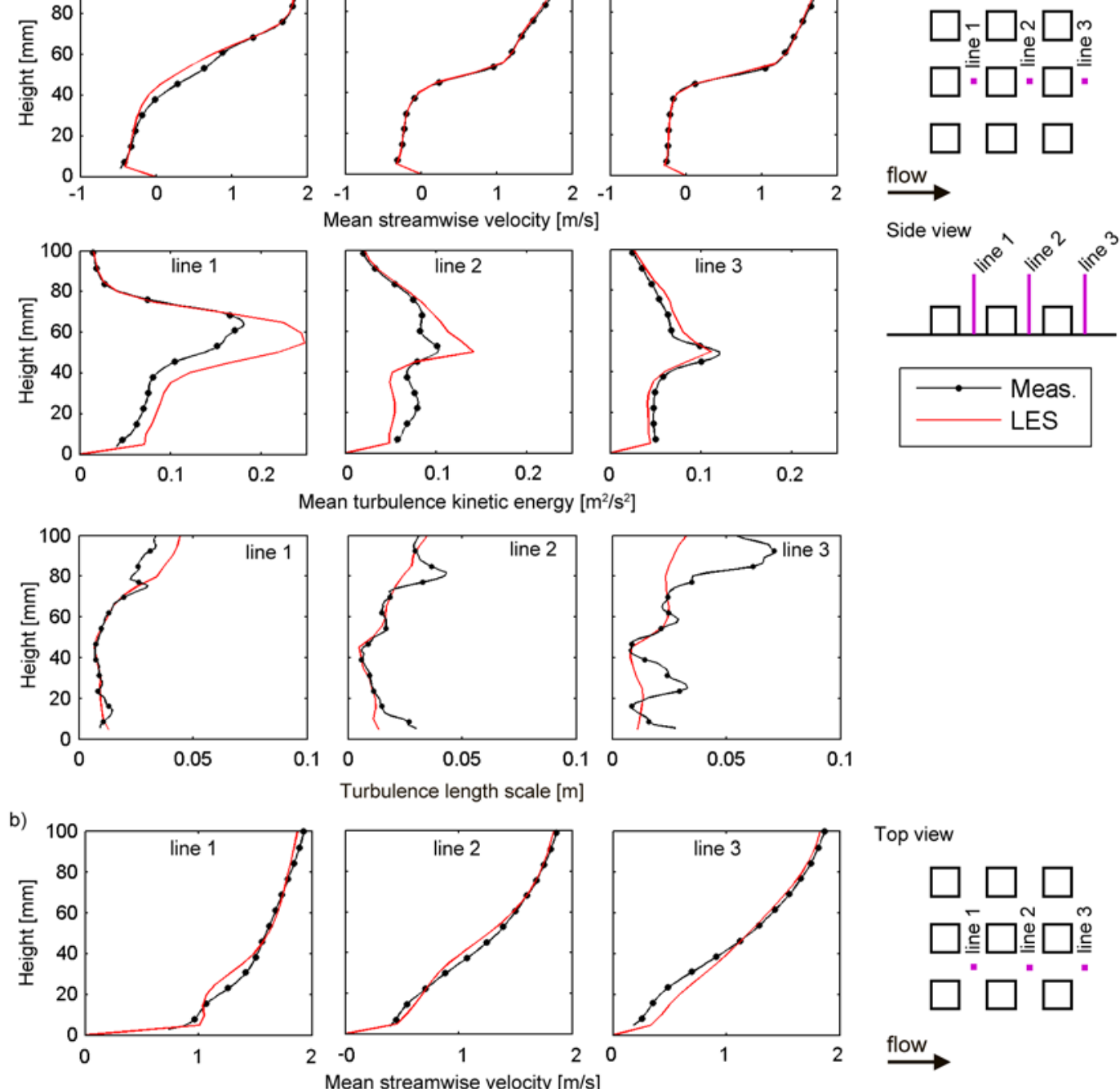

Top view
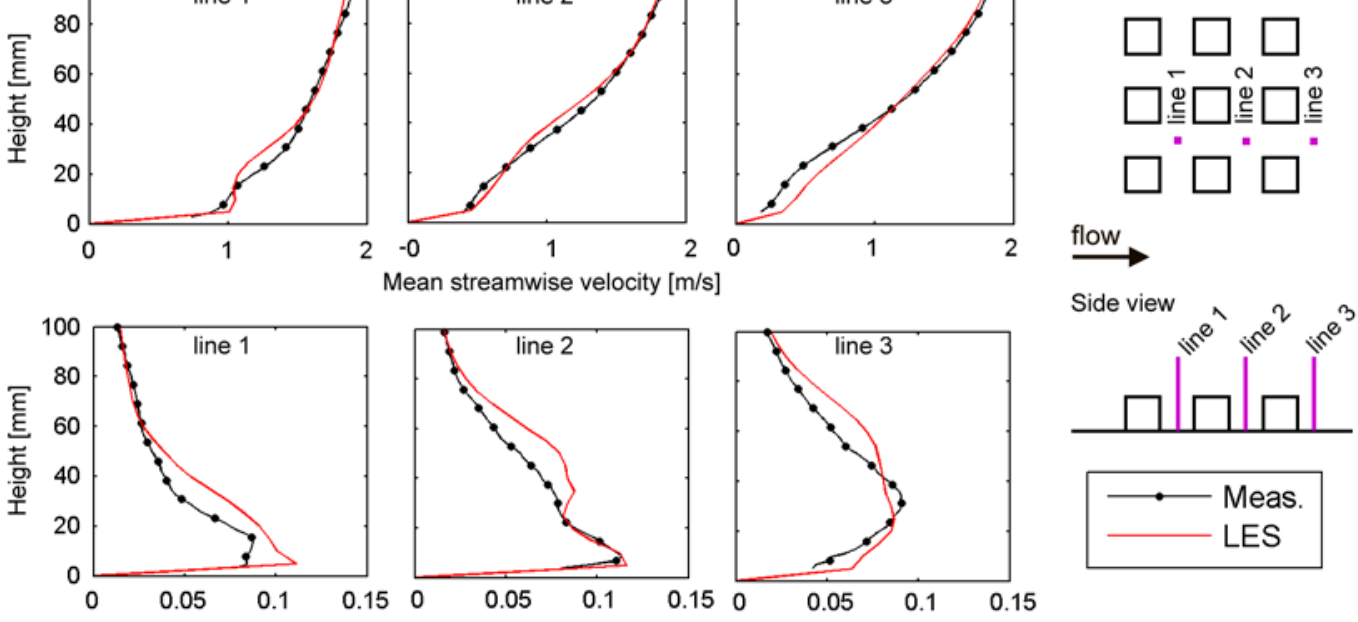

Mean turbulence kinetic energy $\left[\mathrm{m}^{2} / \mathrm{s}^{2}\right]$
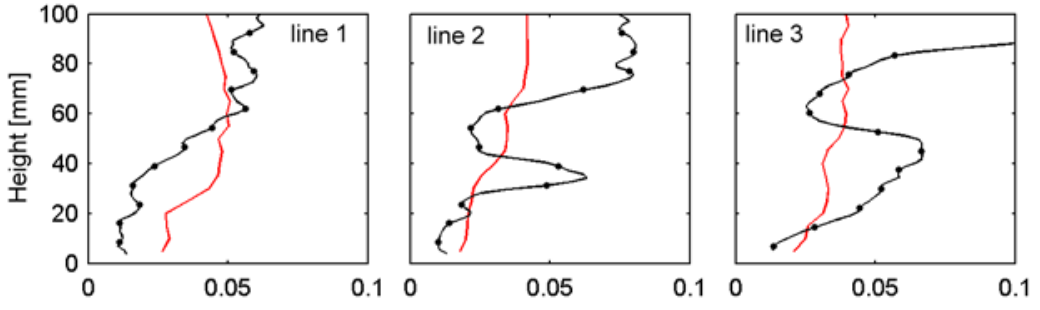

Turbulence length scale [m]

Fig. 2. Comparison of vertical profiles of mean streamwise velocity, turbulence kinetic energy and turbulence length scale along lines 1-3 a) in the vertical center plane and b) in a plane between the rows of cubes. 
a)

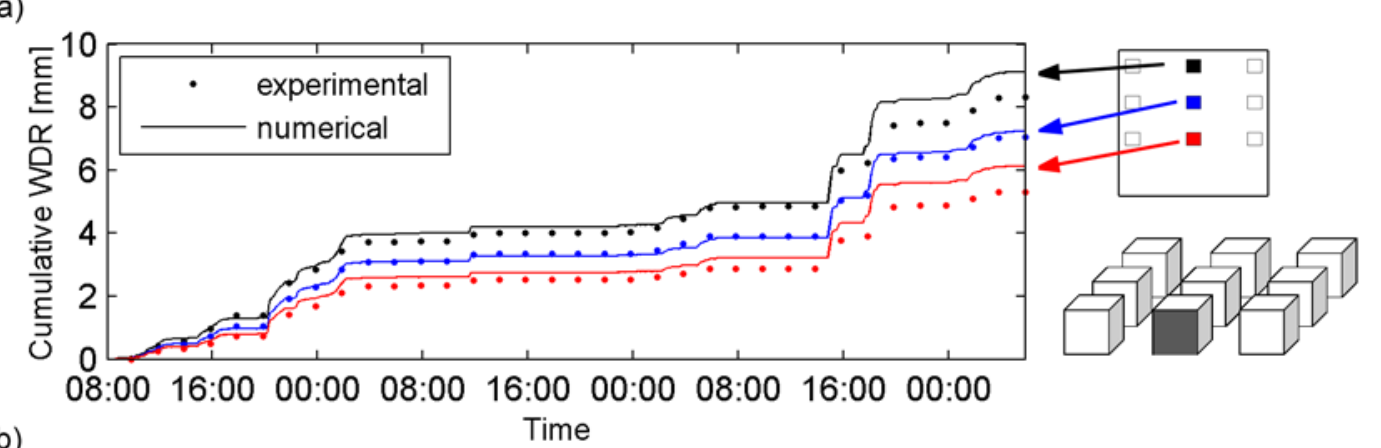

b)

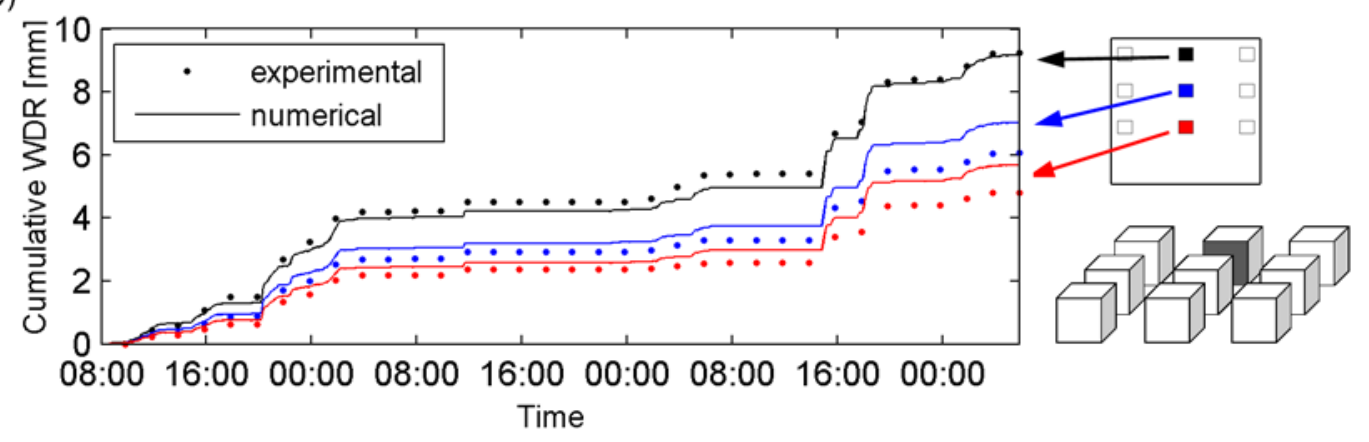

Fig. 3. Comparison of the experimental andnumerical (EM) cumulative WDR amounts on upstream and downstream cubes during the rain event recorded on September 16-19, 2013(Kubilay et al. 2014b).

a)

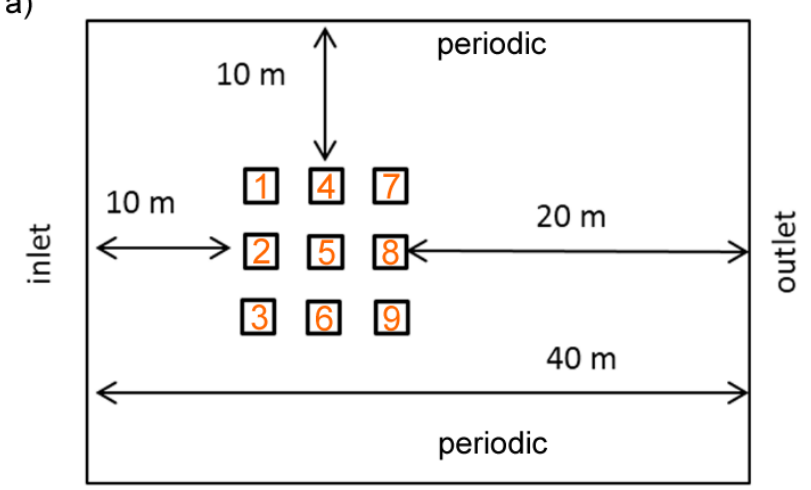

b)

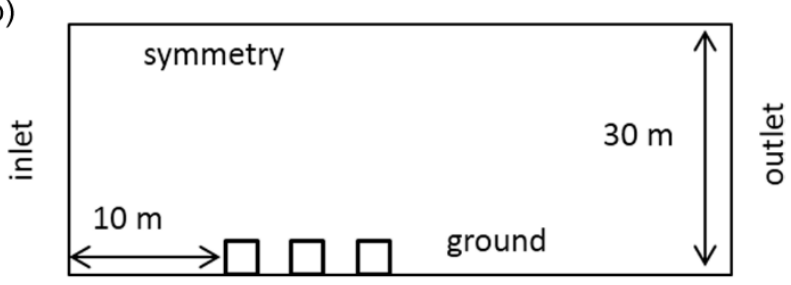

Fig. 4. Schematic representation of the computational domain a) from top and b) from side. 


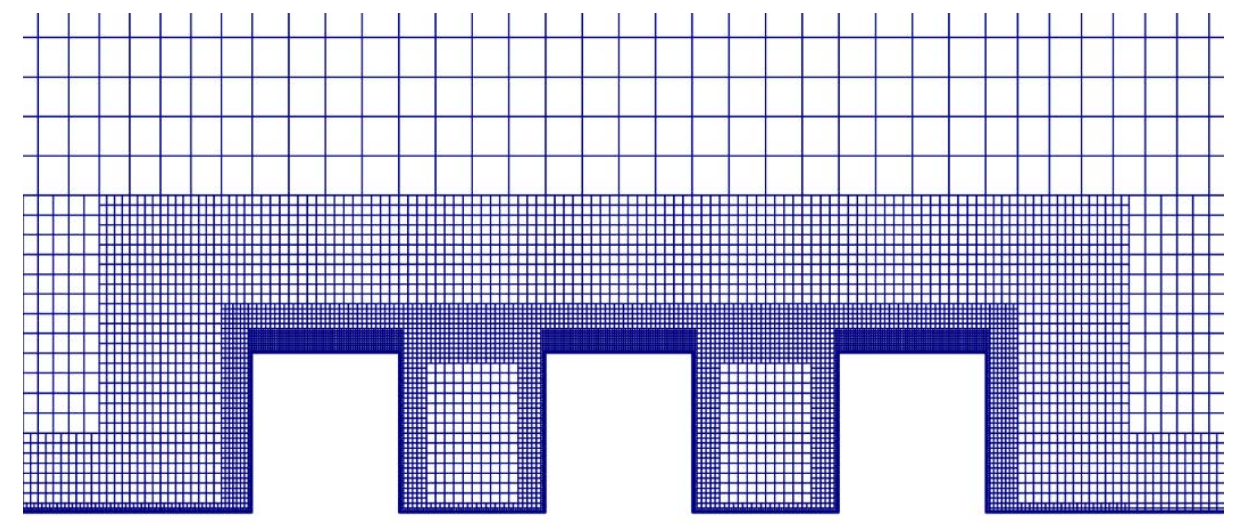

Fig. 5. Cross section of the computational grid for LES (5 022002 cells).

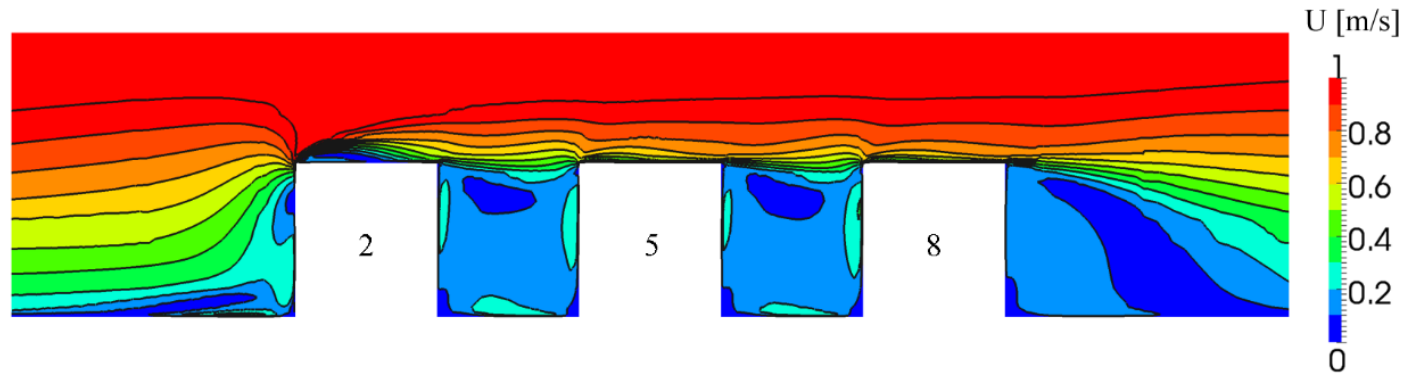

Fig. 6. Contours of magnitude of time-averaged wind speed in the centerplane.

a)

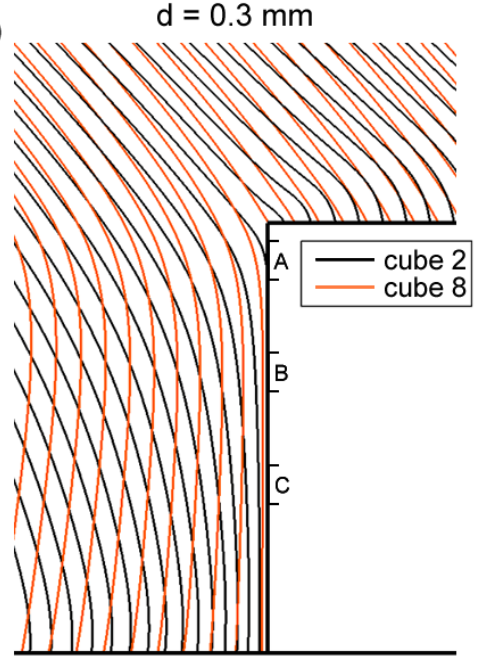

b)

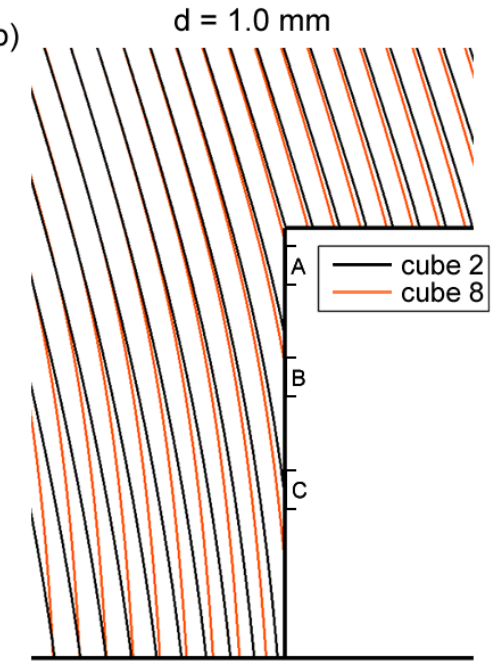

c)

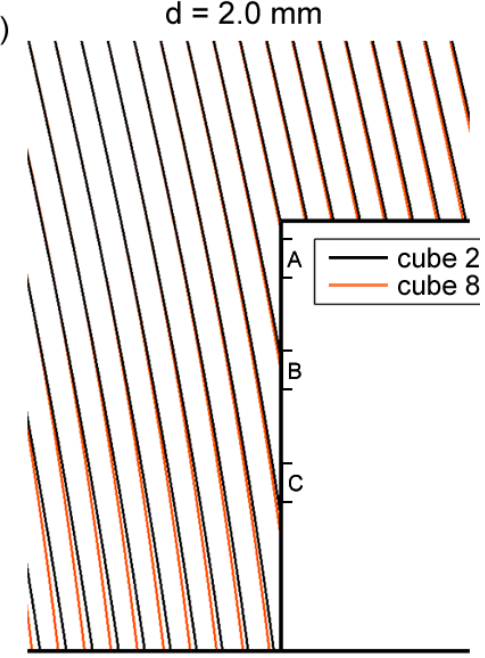

Fig. 7. Comparison of time-averaged streamlines of raindrops of diameters of a) d $=0.3 \mathrm{~mm}$, b) $1.0 \mathrm{~mm}$ and c) $2.0 \mathrm{~mm}$ impinging on cubes 2 and 8 in the vertical centerplane for a reference wind speed of $1 \mathrm{~m} / \mathrm{s}$. 


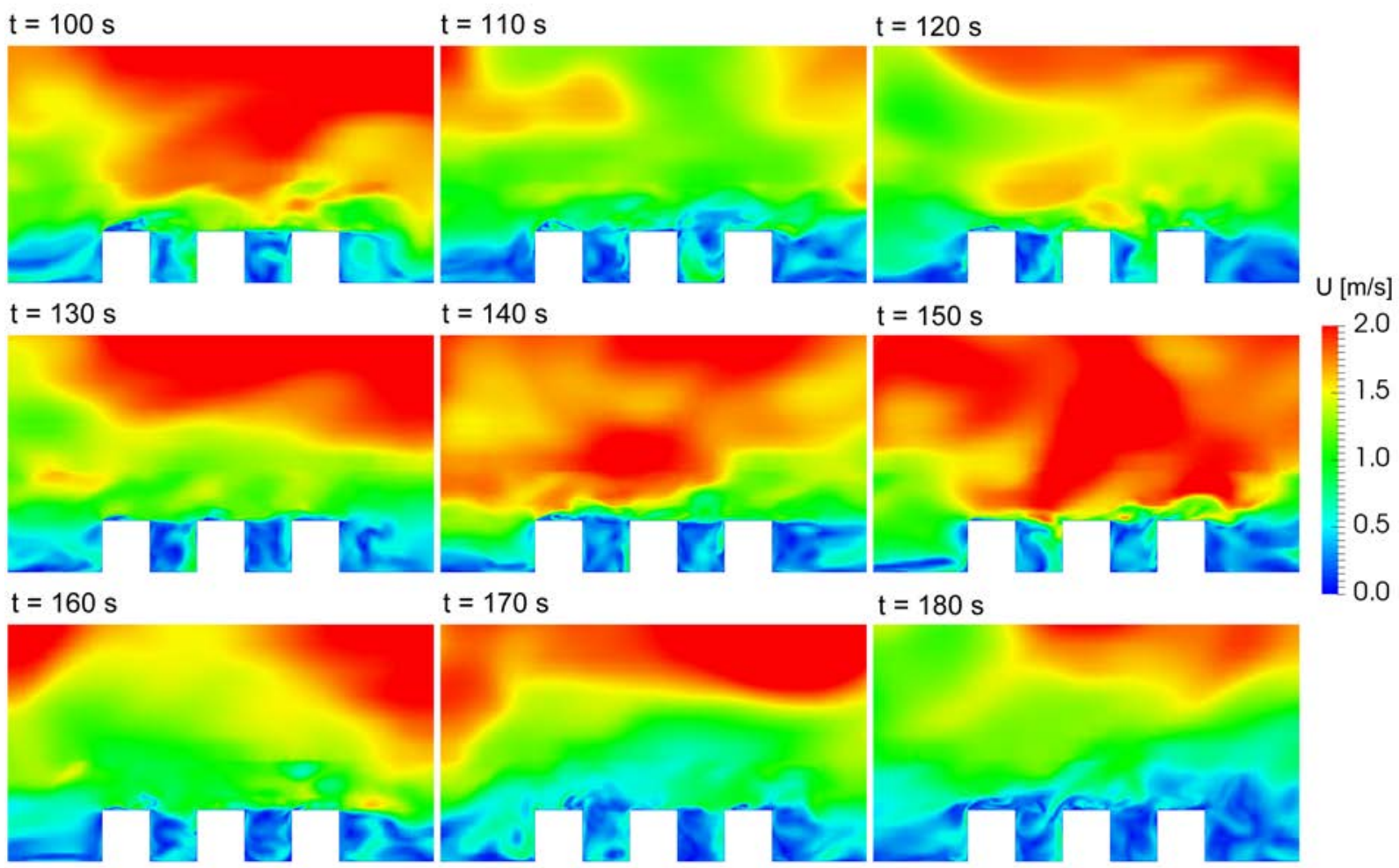

Fig. 8. Contours of magnitude of instantaneous wind speed in the centerplane at time instants 100-180 s.

a)

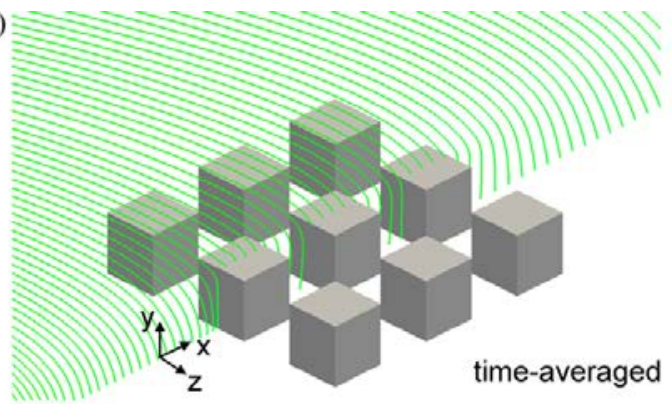

c)

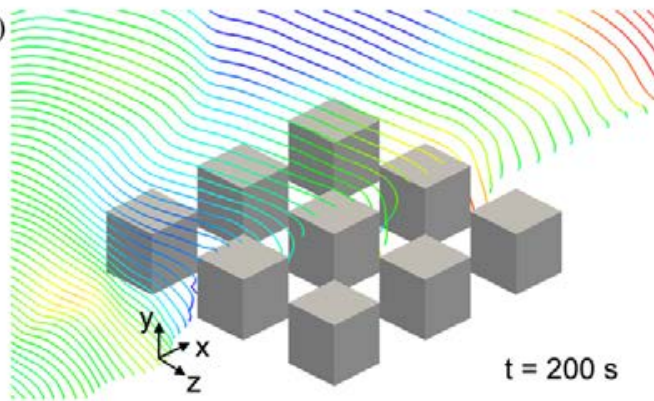

b)

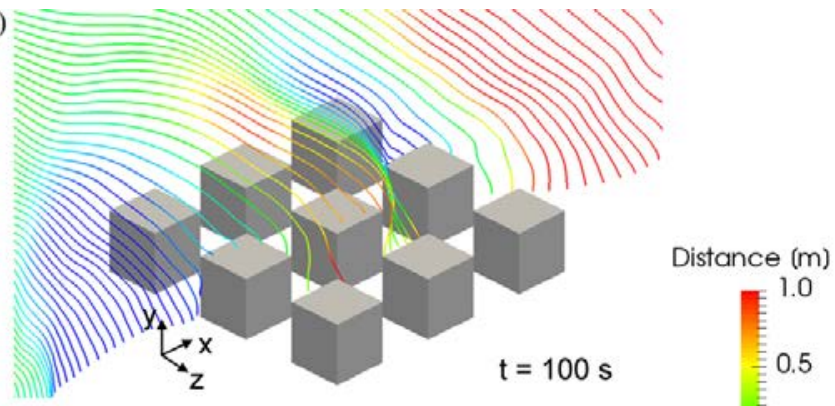

d)

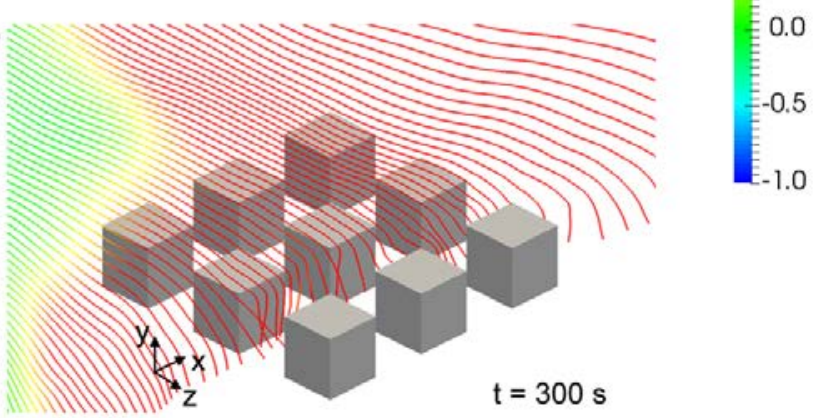

Fig. 9. a) Time-averaged andb-d) instantaneous streamlines at $t=100,200,300 \mathrm{~s}$ for the raindrop size of $0.3 \mathrm{~mm}$. The colorbar shows the distance of streamlines from the vertical centerplane. 
a)

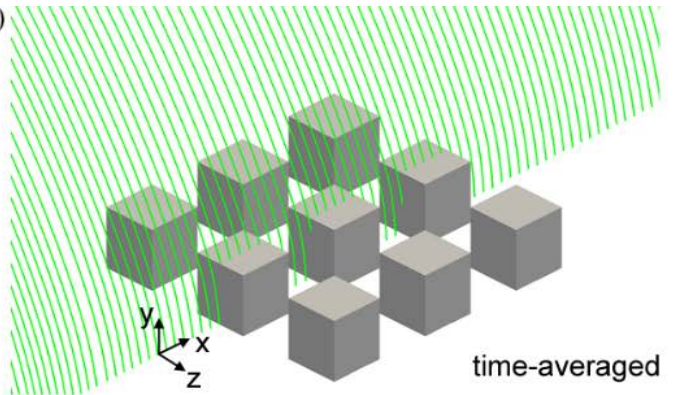

c)

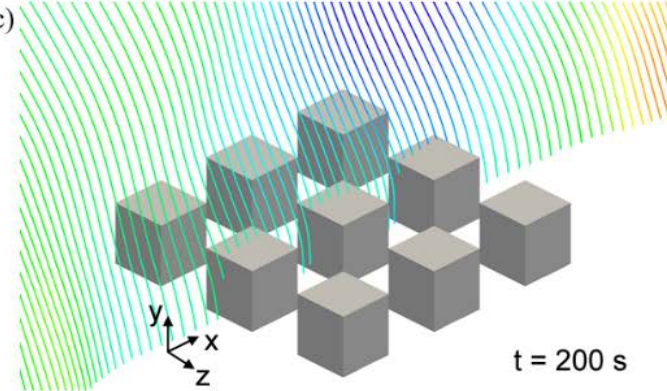

b)

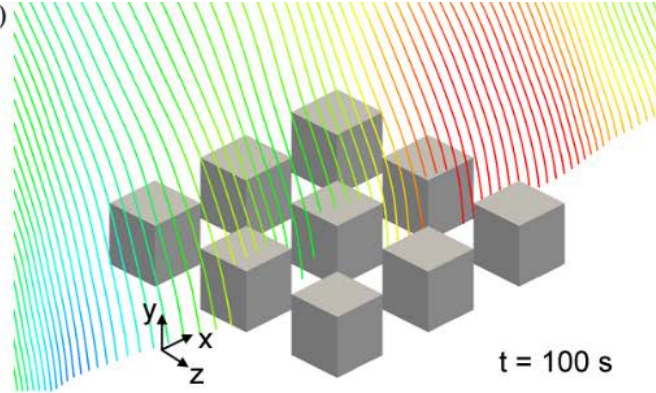

d)

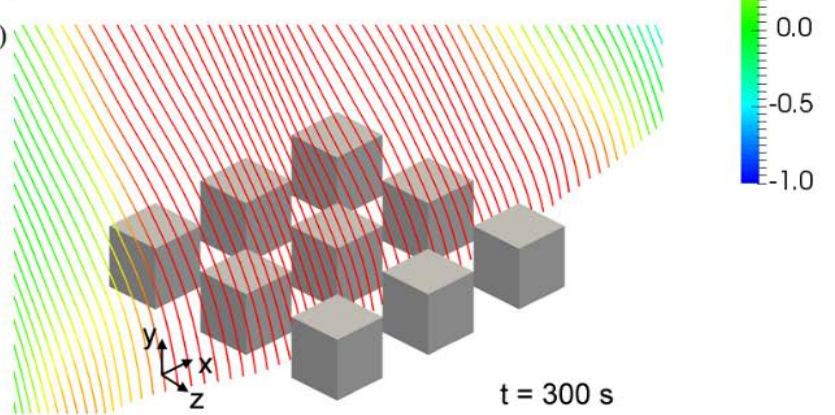

Fig. 10. a) Time-averaged andb-d) instantaneous streamlines at $t=100,200,300 \mathrm{~s}$ for the raindrop size of $1.0 \mathrm{~mm}$. The colorbar shows the distance of streamlines from the vertical centerplane. 

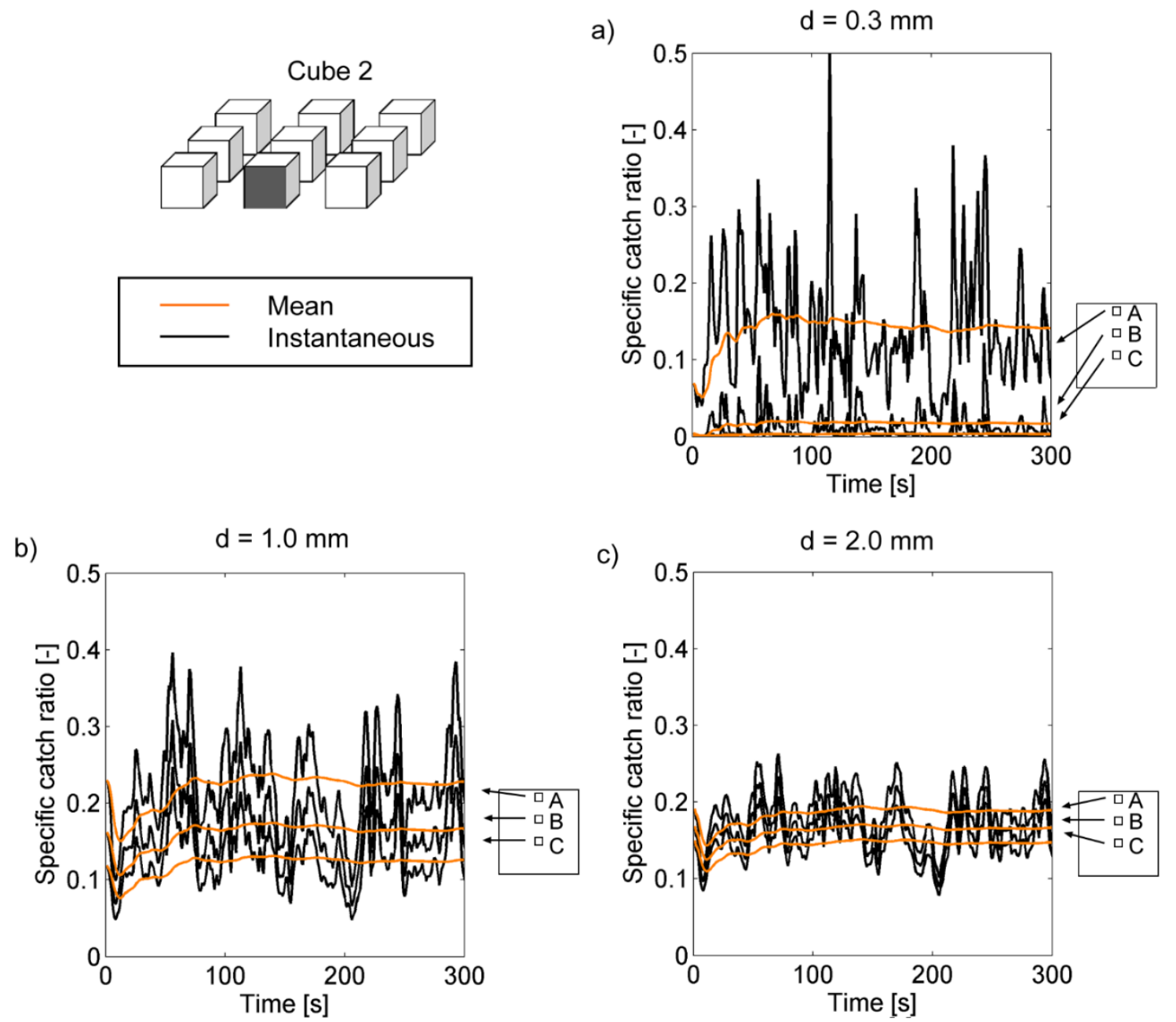

Fig. 11. Instantaneous specific catch ratio values on the windward facade of cube 2, averaged over 3 WDR gauge positions for diameters of size of a) $0.3 \mathrm{~mm}$, b) $1.0 \mathrm{~mm}$ and c) $2.0 \mathrm{~mm}$. 

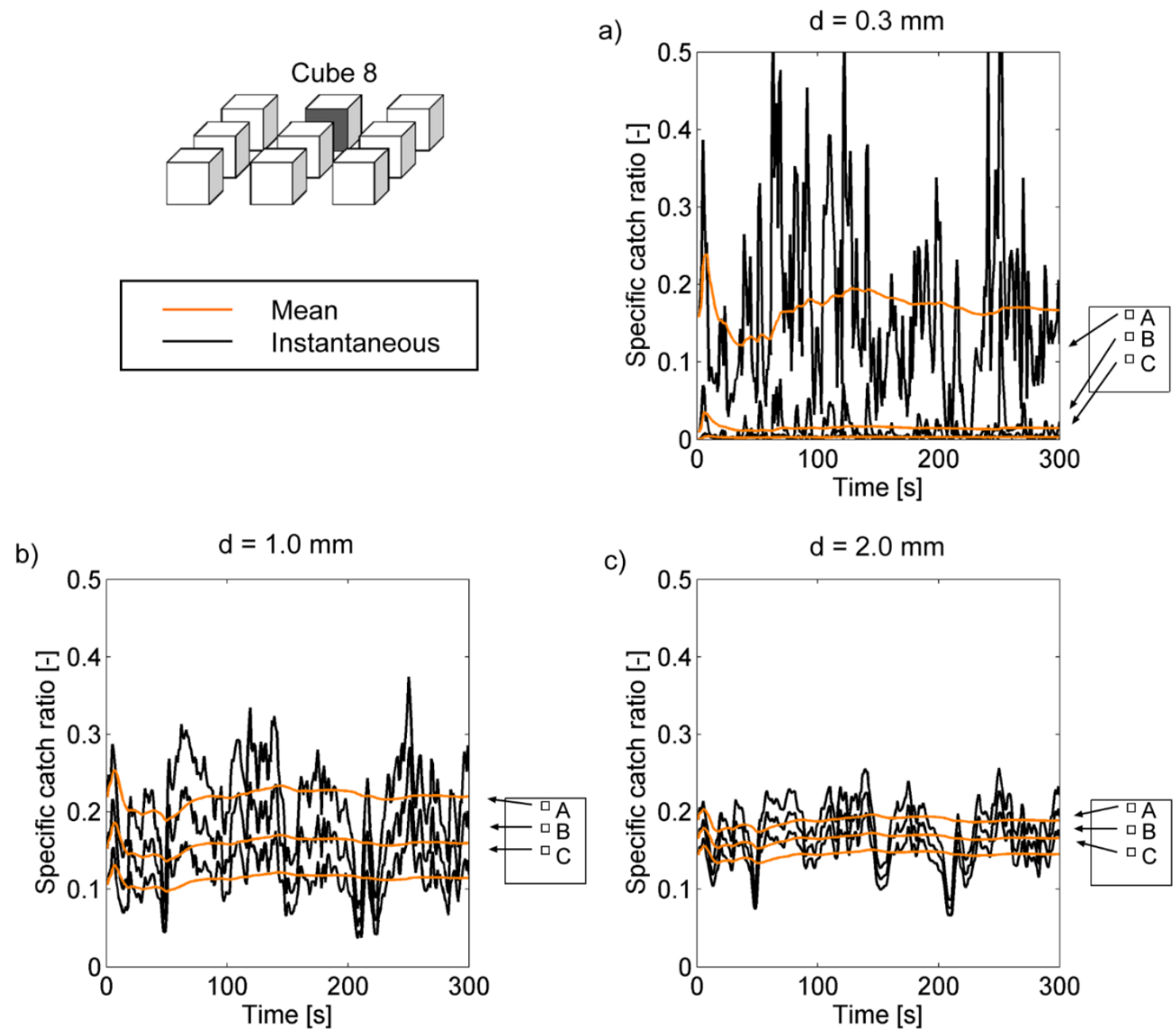

Fig. 12. Instantaneous specific catch ratio values on the windward facade of cube 8, averaged over 3 WDR gauge positions for diameters of size of a) $0.3 \mathrm{~mm}$, b) $1.0 \mathrm{~mm}$ and c) $2.0 \mathrm{~mm}$. 
a)
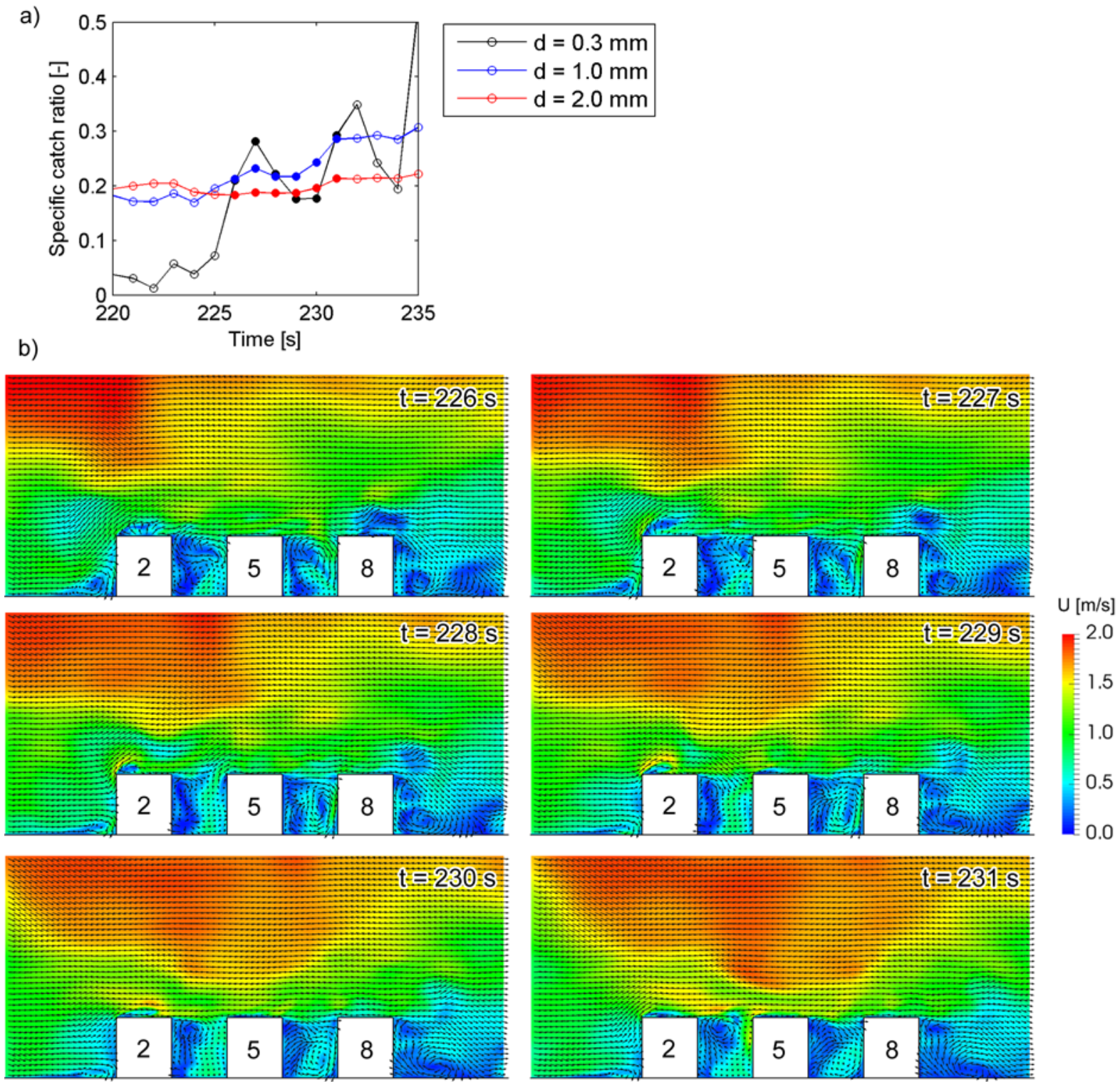

c)
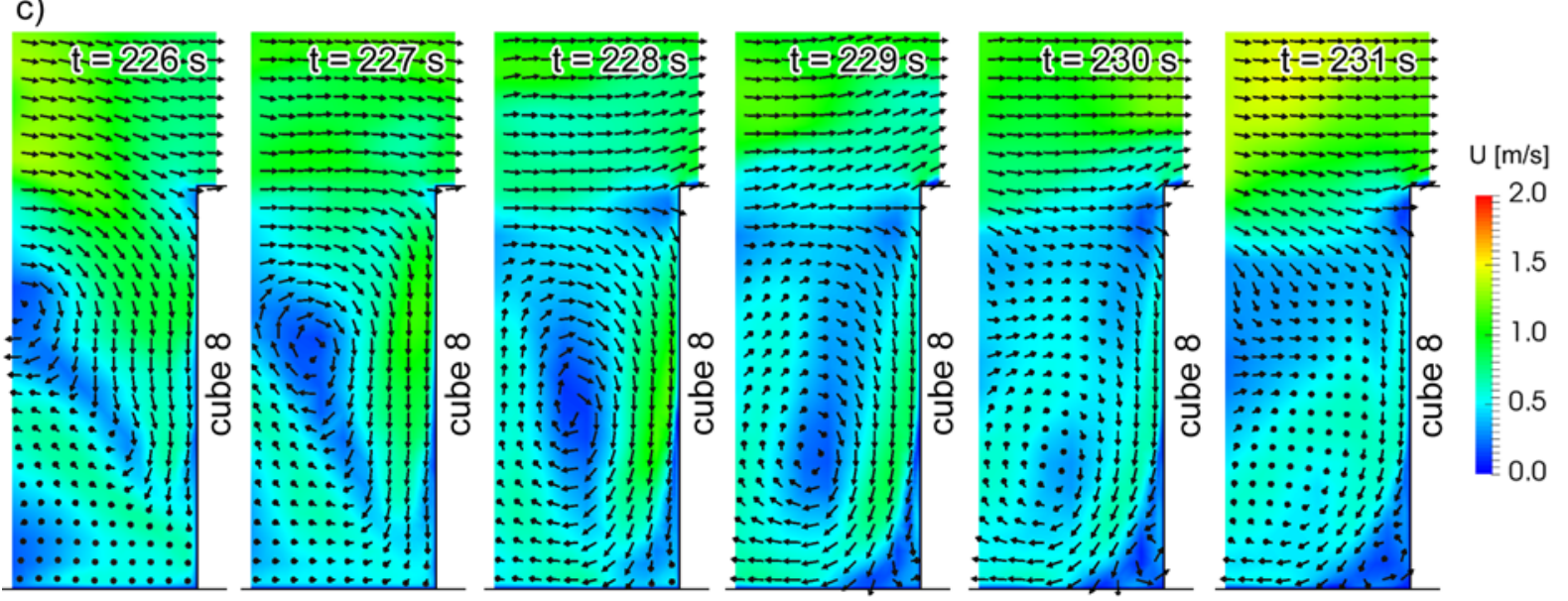

Fig. 13. a) Specific catch ratio for raindrop sizes $\mathrm{d}=0.3,1.0$ and $2.0 \mathrm{~mm}$ for the upper position $\mathrm{A}$ on cube 8 between $\mathrm{t}=220-235 \mathrm{~s}$. b) Instantaneous wind-flow field in the vertical centerplane between $\mathrm{t}=226-231 \mathrm{~s}$ and c) the detail of the wind-flow field upstream of cube 8 . 


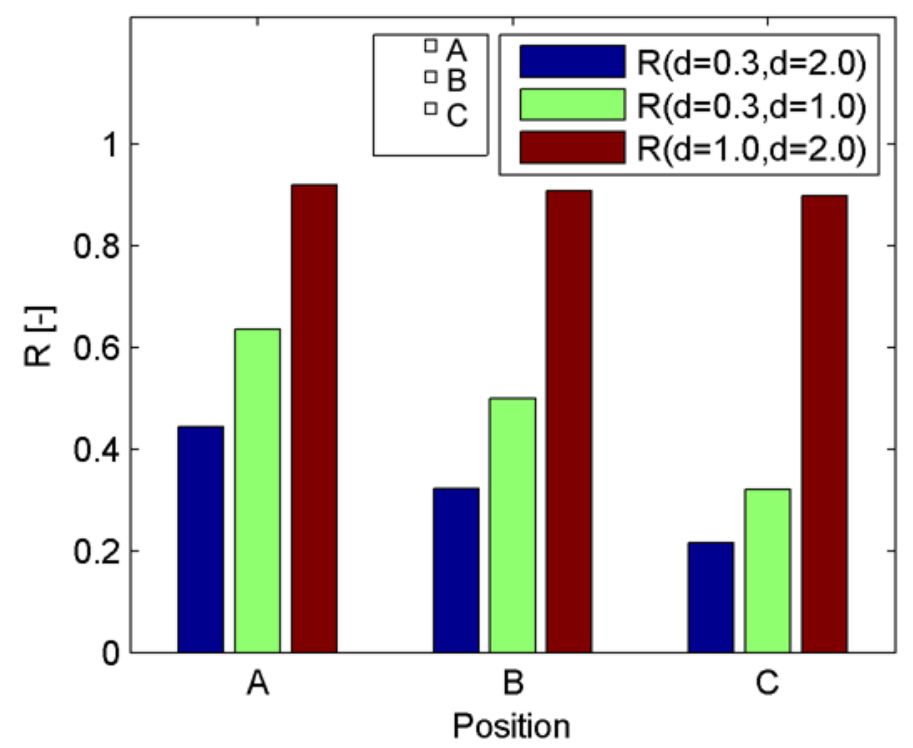

Fig. 14. Correlation coefficient $R\left(\mathrm{~d}_{\mathrm{i}}, \mathrm{d}_{\mathrm{j}}\right)$ of time-resolved specific catch ratio at positions $\mathrm{A}, \mathrm{B}$ and $\mathrm{C}$ on the windward facade of cube 8 between different raindrop sizes. 


\section{Tables}

Table 1. Time-averaged specific catch ratio on cube 2 for $\mathrm{d}=0.3,1.0$ and $2.0 \mathrm{~mm}$. Values within the brackets indicate the standard deviation.

\begin{tabular}{cccc}
\hline time-averaged $\eta_{d}[-]$ & $\begin{array}{c}\text { Upper } \\
\text { position (A) }\end{array}$ & $\begin{array}{c}\text { Middle } \\
\text { position (B) }\end{array}$ & $\begin{array}{c}\text { Lower } \\
\text { position (C) }\end{array}$ \\
\hline$d=0.3 \mathrm{~mm}$ & 0.14 & 0.02 & 0.00 \\
& $(0.08)$ & $(0.02)$ & $(0.01)$ \\
$d=1.0 \mathrm{~mm}$ & 0.23 & 0.17 & 0.13 \\
& $(0.06)$ & $(0.05)$ & $(0.04)$ \\
$d=2.0 \mathrm{~mm}$ & 0.19 & 0.17 & 0.15 \\
& $(0.03)$ & $(0.03)$ & $(0.03)$ \\
\hline
\end{tabular}

Table 2. Time-averaged specific catch ratio on cube 8 for $\mathrm{d}=0.3,1.0$ and $2.0 \mathrm{~mm}$. Values within the brackets indicate the standard deviation.

\begin{tabular}{cccc}
\hline time-averaged $\eta_{d}[-]$ & $\begin{array}{c}\text { Upper } \\
\text { position (A) }\end{array}$ & $\begin{array}{c}\text { Middle } \\
\text { position (B) }\end{array}$ & $\begin{array}{c}\text { Lower } \\
\text { position (C) }\end{array}$ \\
\hline$d=0.3 \mathrm{~mm}$ & 0.17 & 0.01 & 0.00 \\
& $(0.11)$ & $(0.02)$ & $(0.00)$ \\
$d=1.0 \mathrm{~mm}$ & 0.22 & 0.16 & 0.11 \\
& $(0.05)$ & $(0.04)$ & $(0.03)$ \\
$d=2.0 \mathrm{~mm}$ & 0.19 & 0.17 & 0.15 \\
& $(0.03)$ & $(0.03)$ & $(0.02)$ \\
\hline
\end{tabular}

